\title{
Consumption risk sharing over the business cycle: The role of small firms' access to credit markets
}

\author{
Hoffmann, Mathias ; Shcherbakova-Stewen, Iryna
}

\begin{abstract}
Consumption risk sharing among U.S. states increases in booms and decreases in recessions. These business cycle fluctuations in interstate risk sharing are driven mainly by states in which small businesses account for a large share of income or employment. State-level banking deregulation during the 1980s loosened the dependence of interstate risk sharing on the business cycle, mainly through its impact on states with many small firms. Our results establish a major benefit from bank deregulation: small firms' access to credit and, with it, interstate risk sharing have improved mainly when it is most urgently needed: in nationwide economic downturns.
\end{abstract}

DOI: https://doi.org/10.1162/REST_a_00123

Posted at the Zurich Open Repository and Archive, University of Zurich

ZORA URL: https://doi.org/10.5167/uzh-50816

Journal Article

Published Version

Originally published at:

Hoffmann, Mathias; Shcherbakova-Stewen, Iryna (2011). Consumption risk sharing over the business cycle: The role of small firms' access to credit markets. The Review of Economics and Statistics, 93(4):1403-1416.

DOI: https://doi.org/10.1162/REST_a_00123 


\title{
Consumption Risk Sharing over the Business Cycle: the Role of Small Firms' Access to Credit Markets ${ }^{1}$
}

\author{
Mathias Hoffmann ${ }^{2}$ \\ University of Zurich \& CESifo \\ Iryna Shcherbakova-Stewen \\ University of Zurich \\ This version: October 2009 \\ http://www.iew.uzh.ch/itf
}

\begin{abstract}
${ }^{1}$ The authors would like to thank two anonymous referees, Bent Sørensen, Josef Falkinger, Jean Imbs, Henri Loubergé, Mark Watson (the editor) and Fabrizio Zilibotti for discussions, comments and suggestions. We are also grateful to seminar participants at University of Zurich, Free University of Berlin, GIIDS Geneva, Hong Kong Monetary Authority, Kobe University, NCCR-FinRisk 2007 Doctoral Workshop in Gerzensee, CSRG 10th Anniversary Conference in Warwick, 2008 meetings of the Swiss Society of Economics and Statistics and 2009 Macroeconomic Research Meeting in Tubingen. Hoffmann's work on this paper is also part of the project The International Allocation of Risk in the framework of special research center SFB 475 funded by Deutsche Forschungsgemeinschaft and of the MacroFinance project of UZH's research priority program in Finance and Financial Markets

${ }^{2}$ Both authors are at University of Zurich, Institute for Empirical Research in Economics, Chair of International Trade and Finance, Zuerichbergstrasse 14, CH-8032 Zurich. E-Mail: mathias.hoffmann@iew.uzh.ch and iryna.stewen@iew.uzh.ch
\end{abstract}




\begin{abstract}
Consumption risk sharing among US federal states increases in booms and decreases in recessions. These business-cycle fluctuations in interstate risk sharing are driven mainly by states in which small firms account for a large share of income or employment. State-level banking deregulation during the 1980s seems to have loosened the dependence of aggregate risk sharing on the business cycle, and this effect is again strongest in states with many small firms. Our results support the view that better access to credit markets may have made it easier for the owners of small firms to smooth income in the face of adverse cash-flow shocks to their business. They also suggest a major additional benefit from banking deregulation: access to bank credit may have become more reliable and more easily available when households and firms need it most urgently—in economic downturns.
\end{abstract}

Keywords: INTERSTATE RISK SHARING, REGIONAL BUSINESS CYCLE, PROPRIETARY INCOME, SMALL BUSINESSES, STATE BANKING DEREGULATION

JEL classification: E32, E44, F3 


\section{Introduction}

Consumption risk sharing among US federal states increases in booms and decreases in recessions. We find that small firms play an important role in explaining this stylized fact: business-cycle fluctuations in interstate risk sharing are most pronounced in states in which small firms account for a large share of income or employment. State-level banking deregulation during the 1980s has, however, dampened this dependence of aggregate risk sharing on the business cycle. Our findings support the view that banking deregulation has considerably improved credit market access for small firms, in particular in recessions, when it is most urgently needed.

Our analysis places itself at the intersection of two important recent strands of the literature. The first strand emphasizes that the degree to which certain household groups and small firms have access to financial markets varies dramatically over the business cycle. In particular, a considerable body of theoretical and empirical work on the financial accelerator ${ }^{1}$ has argued that tightening collateral constraints in credit markets may act as a potentially powerful amplification mechanism for aggregate shocks. Gertler and Gilchrist (1994) were among the first to illustrate empirically that small firms with their strong dependence on bank finance are particularly exposed to such shocks.

We provide a comprehensive taxonomy of business-cycle variation in interstate risk sharing. First, we show that the extent to which interstate risk sharing varies with the aggregate output cycle

\footnotetext{
${ }^{1}$ We will not attempt to survey this work here. Leading examples include Bernanke (1983), Bernanke and Gertler (1989) and Kiyotaki and Moore (1997).
} 
is quantitatively important: over our sample period, which ranges from 1963 to 2005, on average almost 80 percent of state-specific shocks to output are shared across state borders. However, this average masks considerable variation over time: at the trough of the typical NBER recession during that period, the fraction of risk shared was almost 20 percentage points below this level. This dependence of aggregate risk sharing on the business cycle is robust to controls for other factors such as stock market and housing price fluctuations, which, as recently argued by Lustig and van Nieuwerburgh (2005), may also affect the ability of households to share risk across regional borders.

Secondly, we identify the sources of the procyclical variation in interstate risk sharing. Specifically, we ask through which channels risk is shared and how the contribution of these channels varies over time. Following Asdrubali, Sørensen and Yosha (1996) we distinguish between three channels of risk sharing: income smoothing (through interstate flows of capital and labor income), fiscal transfers and consumption smoothing through personal saving and dissaving. As the main source of the procyclicality in aggregate consumption risk sharing, we identify strong procyclical fluctuations in the extent to which a region's households can smooth consumption through saving and dissaving. Importantly, this very characteristic pattern of risk sharing over the business cycle is determined mainly by federal states where small businesses are particularly prevalent as employers, or where the income of small business owners accounts for a large share of state personal income.

To shed more light on the role of small businesses in the time 
variation in aggregate risk sharing, we connect to a second strand of the literature. Starting with Jayaratne and Strahan (1996), a series of studies has exploited the experience of US state-level banking deregulation during the 1970s and 1980s as a natural laboratory in which to study the effect of liberalization on growth, the comovement of regional business cycles (Morgan, Rime and Strahan (2004)) and, more recently, risk sharing (Demyanyk, Ostergaard and Sørensen (2007), Acharya, Imbs and Sturgess (2007)). We build on these papers in arguing that this wave of deregulation has had a significant impact on small firm access to credit: small firms typically cannot issue stocks or bonds, and therefore rely heavily on bank finance. The key aspect we emphasize here is that this makes them vulnerable to changes in local credit market conditions that tend to worsen in downturns and to improve in booms. At the same time, the business and private finance of small business owners are closely intertwined, so that fluctuations in the access to business credit are also likely to affect the ability to smooth personal consumption over time. State-level banking deregulation transformed a highly fragmented, localized banking system into a system with larger banks that can pool funds across local and state boundaries. We conjecture that this makes the availability of credit less dependent on the phase of the business cycle, and that small firms would be prime beneficiaries of such a development.

Our results provide strong support for this hypothesis. We document that intrastate banking deregulation has dramatically lowered the variability of risk sharing over the cycle: before deregulation, each additional percentage point of GDP growth increased aggre- 
gate risk sharing by around $3-4$ percentage points. This variability in the extent to which state-level idiosyncratic risks can be shared across the nation has almost vanished as a result of the abolition of intrastate bank branching and merger restrictions. Again, small firms seem to have played an important role in transmitting the effects of this deregulation to the real economy: the procyclical pattern in risk sharing is reduced most strongly in those states where small businesses account for a large share of income or employment.

This paper is probably most closely related to Demyanyk, Ostergaard and Sørensen (2007), who showed that interstate income smoothing increased by around 15 percentage points on average following banking deregulation. Our results here suggest that the impact of banking deregulation on the variability of risk sharing is easily of equal importance quantitatively: banking deregulation has made consumption risk sharing much steadier over the cycle. Consumption risk is almost 20 percentage points higher than it used to be before deregulation in the average recession.

The reduction in the variability of interstate risk sharing that we document here is a potentially important source of the aggregate benefits from banking deregulation. Small firms are especially exposed to aggregate shocks (Gertler and Gilchrist (1994)) and it is therefore particularly important that they can borrow in recessions. Our findings support the view that banking deregulation has generally improved credit market access for small firms in recessions. There is a range of possible mechanisms through which these improvements could have been brought about. For example, banks 
could have extended credit lines (or modified credit contracts) for existing firms. Furthermore, they could have more readily provided credit to new firms, or they may have become more inclined to engage in relationship lending by not taking action against delinquent borrowers during recessions in the hope of being compensated in the next economic upswing. ${ }^{2}$ We do not attempt to distinguish between these mechanisms in detail because we believe them to be complementary. All are consistent with our findings here.

The remainder of the paper is structured as follows: in the next section, we introduce our empirical framework and use it to document the procyclical nature of aggregate risk sharing. We also present our data and the details of the empirical implementation. In Section 3, we discuss our empirical results. Section 4 concludes.

\section{Consumption risk sharing over the business cycle}

We measure consumption risk sharing through panel regressions of the form:

$$
\Delta \log \frac{C_{t}^{k}}{C_{t}^{*}}=\beta_{U}\left[\Delta \log \frac{G S P_{t}^{k}}{G S P_{t}^{*}}\right]+\tau_{U t}+\delta_{U}^{k}+\alpha_{U}+\varepsilon_{U t}^{k}
$$

where $C_{t}^{k}$ is per capita consumption in federal state $k$ in period $t$, $G S P_{t}^{k}$ is state output ('gross state product') per head and the asterisk denotes the national per capita average of the respective variable. The terms $\tau_{U t}, \delta_{U}^{k}, \alpha_{U}$ and $\varepsilon_{U t}^{k}$ stand for the time and state fixed effect, a constant and the error term respectively. In such a regres-

\footnotetext{
${ }^{2}$ We thank an anonymous referee for suggesting these examples.
} 
sion, we can think of the estimate of $\beta_{U}$ as the amount of uninsured idiosyncratic output risk.

Regressions such as (1) by now have some tradition in both the micro- and the macroeconomic literature. Mace (1991), Cochrane (1991) and Townsend (1994) were the first to suggest regressions similar to (1) on household-level data as a test of the null of complete markets. Assume that each state is represented by a stand-in consumer and that we can associate changes in marginal utility with consumption growth (as is the case under constant relative risk aversion). Then, consumption growth should be independent of a region's business-cycle risks if financial markets are completeregressions of the form (1) should yield a coefficient of zero. More recently, Asdrubali, Sørensen and Yosha (1996) have argued that the estimate of $\beta_{U}$ may be more generally informative even if markets are incomplete: in panel regressions, $\beta_{U}$ is regularly between 0 and unity, so that $1-\beta_{U}$ can straightforwardly be interpreted as the share of the average region's idiosyncratic output risk that gets laid off in financial markets, whereas $\beta_{U}$ is the portion of nondiversified idiosyncratic risk faced by the average region.

Estimates of $\beta_{U}$ based on regional data reported in the literature tend to fall into the range between $0.2-0.3$, therefore roughly a quarter to a third of a region's idiosyncratic output risk remains uninsured. $^{3}$ Based on our US state-level data set here, we obtain an estimate of just below 0.2 . Such estimates are typically based on panel regressions such as (1) and they do not generally allow for the possibility that the amount of risk sharing that a group of regions

\footnotetext{
${ }^{3}$ See Asdrubali et al. (1996), Crucini (1999).
} 
achieves may actually be varying over time.

In this paper, we argue that aggregate risk sharing varies over the business cycle. This could be because certain groups of households may find it harder to obtain consumption insurance in financial markets during recessions than during booms. In particular, many small firms rely heavily on access to bank loans, i.e. to credit markets, to smooth fluctuations in business cash flow. ${ }^{4}$ Fluctuations in the availability of credit over the business cycle may therefore affect the degree of consumption risk sharing that the proprietors of small businesses and possibly also their employees can achieve. In this way, credit market restrictions may translate into fluctuations in aggregate risk sharing across regions.

Figure 1 presents the first evidence of business-cycle variation in interstate risk sharing: the figure plots a sequence of crosssectional estimates of the coefficient $\beta_{U}$. To obtain this sequence, we run the regression (1) as a cross-sectional regression for each year in our sample period that ranges from 1964 to $2005:^{5}$

$$
\Delta \widetilde{c}_{t}^{k}=\beta_{U}(t) \Delta \widetilde{g s p} p_{t}^{k}+\tau_{U t}+\varepsilon_{U t}^{k}
$$

where $t=1964, \ldots, 2005, \tau_{U t}$ is the constant of the time $t$ crosssectional regression and $\varepsilon_{U t}^{k}$ is again the disturbance term. Here, and in the remainder of the paper, we use lower-case letters with

\footnotetext{
${ }^{4}$ It is well documented that credit market frictions tend to hit small firms harder than bigger firms that can issue their own bonds or may even be able to raise equity in stock markets. Gertler and Gilchrist (1994) showed that the credit channel of monetary policy has a much stronger impact on small firms than on bigger firms.

${ }^{5}$ Cross-sectional risk-sharing regressions go back to Cochrane (1991). Sequences of such regressions have previously been used by, e.g. Sørensen et al. (2007) to study the impact of financial globalization on international risk sharing.
} 
a tilde to denote logarithmic deviations from the US aggregate, so that $\Delta \widetilde{c}_{t}^{k}=\Delta \log \left[C_{t}^{k} / C_{t}^{*}\right]$ and $\Delta \widetilde{g s p}_{t}^{k}=\Delta \log \left[G S P_{t}^{k} / G S P_{t}^{*}\right]$. The solid line in Figure 1 represents the sequence $\left\{\beta_{U}(t)\right\}$, the dashed line is aggregate US real GDP growth. The sequence of risk-sharing coefficients has a mean of roughly 0.2 but it fluctuates dramatically over the cycle: $\beta_{U}(t)$ displays a negative correlation $(-0.3)$ with aggregate GDP growth-the share of nondiversified state-level idiosyncratic risk increases in recessions and decreases in booms.

Closer inspection of Figure 1 reveals that the negative correlation between $\beta_{U}(t)$ and GDP growth is stronger in the first half of the sample period: for the period until 1984 it is -0.44 , thereafter it drops to -0.13 . We argue that this decline in the comovement of $\beta_{U}(t)$ with the business cycle is the result of banking deregulation at the state level during the 1970s and 1980s. ${ }^{6}$ Figure 2 illustrates this point. It provides a Burns-Mitchell-type diagram that shows the typical behavior of $\beta_{U}(t)$ around the trough of an NBER recession, distinguishing between states that had already deregulated their bank branching restrictions and those that had not. The impact of deregulation is clearly visible: the behavior of $\beta_{U}(t)$ for the deregulated states is flat around recession events at a value of around 0.2. This value is almost identical to the estimate for the representative state when we estimate $\beta_{U}$ from a panel regression such as (1). Conversely, for the group of states that are still regulating bank branching, the estimate of the fraction of unshared risk rises and peaks at 0.36 in the year of the business-cycle trough. Only a year after risk sharing increases again, $\beta_{U}(t)$ falls back to the

\footnotetext{
${ }^{6}$ Note that 1984 not only marks the mid-point of our sample but also the year in which exactly half of all states had deregulated.
} 
nationwide long-term average of around 0.2. Hence, at the trough of the average NBER recession risk sharing was almost 20 (exactly: $16=(0.36-0.2) \times 100)$ percentage points below its long-run mean for those states that had not yet deregulated their bank branching restrictions.

The fact that business-cycle variation in risk sharing is dampened by bank deregulation may suggest that certain groups of firms and households that were previously unable to obtain credit in recessions may now have obtained better access to finance. Consistent with this conjecture, we find that the cycle in interstate risk sharing is driven mainly by those states where small businesses are particularly important. Figure 3 plots the sequence of $\beta_{U}(t)$, estimated once from the group of states with above-median incidence of small businesses and once from the lower half of the distribution. Over the period before the majority of states deregulated (1964-83) there is a pronounced negative correlation with GDP mainly for the group of states with lots of small businesses ( -0.47$)$, whereas for the other group this correlation was close to zero $(-0.09)$.

\subsection{Capturing time and state variations in interstate risk sharing}

We now model business-cycle variation in interstate risk sharing more formally. To this end, we augment the basic panel regression (1) to include an interaction with aggregate, US-wide GDP growth:

$$
\Delta \widetilde{c}_{t}^{k}=a_{U} \times \Delta \widetilde{g s p_{t}^{k}}+b_{U} \Delta g d p_{t} \times \Delta \widetilde{g s p_{t}^{k}}+\boldsymbol{d}_{U t}^{k \prime} \mathbf{1}+\varepsilon_{U t}^{k}
$$


so that $\beta_{U}(t)=a_{U}+b_{U} \times \Delta g d p_{t}$ can be interpreted as the fraction of unshared risk that now varies over time. Here, to save space, we have collected time and state fixed effects and the constant into the vector $\boldsymbol{d}_{U t}^{k \prime}=\left[\begin{array}{lll}\tau_{U t} & \delta_{U}^{k} & \alpha_{U}\end{array}\right]$ and 1 is a vector of ones. Regressions of this form are our main tool of analysis in the remainder of the paper. If risk sharing increases in booms and decreases in recessions, we would expect $b_{U}<0$. We pursue two specific hypotheses concerning the strength of this cyclical pattern in interstate risk sharing, i.e. on the magnitude of $b_{U}$ : we argue that the procyclical pattern in risk sharing occurs mainly in states where small businesses are important. Second, we show that this cyclical pattern is dampened-in fact it almost vanishes—once a federal state liberalizes its bank branching laws.

To document these facts, we adopt two different approaches. A directly intuitive one is to split our sample by time (before/after deregulation) and into groups of states that differ by small business importance. A second, more formal approach augments equation (3) to allow risk sharing to vary across federal states and across time as a function of small business prevalence or deregulation as well as other characteristics. To capture this variation, we generalize the parameterization in (3) above:

$$
\beta_{U}^{k}(t)=\Delta g d p_{t}\left[\mathbf{z}_{t}^{k \prime} \boldsymbol{b}_{U}\right]+\mathbf{z}_{t}^{k \prime} \boldsymbol{a}_{U}
$$

where $\boldsymbol{b}_{U}, \boldsymbol{a}_{U}$ are now coefficient vectors that load on the vector of state-time characteristics $\mathbf{z}_{t}^{k}$. The term $\mathbf{z}_{t}^{k \prime} \boldsymbol{b}_{U}$ corresponds to $b_{U}$ above in that it captures the cross-state and time variation in the 
sensitivity of interstate risk sharing to aggregate business-cycle fluctuations. Conversely, the term $\mathbf{z}_{t}^{k \prime} \boldsymbol{a}_{U}$ is analogous to $a_{U}$ and captures the effect of the state-time characteristics on the long-term average level of risk sharing. We partition $\mathbf{z}_{t}^{k \prime}=\left[1, \mathbf{x}_{t}^{\prime}, \mathbf{u}^{\prime k}, \mathbf{y}_{t}^{\prime k}\right]$, where $\mathbf{x}_{t}^{\prime}$ is a vector of common time-varying characteristics and $\mathbf{u}^{\prime k}$ is a vector of time-invariant state-specific characteristics whereas $\mathbf{y}_{t}^{\prime k}$ collects all characteristics that vary across both time and state.

Plugging the specification for $\beta_{U}^{k}(t)$ into the basic panel risksharing regression (1), we obtain a set of interaction terms, $\Delta g d p_{t}\left[\mathbf{z}_{t}^{k \prime} \boldsymbol{b}_{U}\right] \times$ $\Delta \widetilde{g s p} p_{t}^{k}$ and $\mathbf{z}_{t}^{k \prime} \boldsymbol{a}_{U} \times \Delta \widetilde{g s p_{t}^{k}}$ respectively. The equation we effectively estimate then has the form:

$$
\Delta \widetilde{c}_{t}^{k}=\Delta g d p_{t}\left[\mathbf{z}_{t}^{k \prime} \boldsymbol{b}_{U}\right] \times \widetilde{g s p}_{t}^{k}+\mathbf{z}_{t}^{k \prime} \boldsymbol{a}_{U} \times \widetilde{g s p}_{t}^{k}+\mathbf{y}_{t}^{k \prime} \boldsymbol{c}_{U}+\boldsymbol{d}_{U t}^{k \prime} \mathbf{1}+\varepsilon_{U t}^{k}
$$

To avoid spurious effects on the higher order interaction terms between $\mathbf{z}_{t}^{k}$ and $\Delta \widetilde{g s p}_{t}^{k}$ this specification also includes first-order terms of those characteristics in $\mathbf{z}_{t}^{k}$ that vary both across time and state (i.e. $\mathbf{y}_{t}^{k}$ ). The vector $c_{U}$ contains the associated regression coefficients. ${ }^{7}$

We now illustrate how we make use of this general framework. For example, to measure the impact of state deregulation on risk sharing we use dummy variables, $S D_{t}^{k}$, that are zero before and unity after a federal state has deregulated. Then letting $\mathbf{z}_{t}^{k \prime}=\left[1, S D_{t}^{k}\right]$

\footnotetext{
${ }^{7}$ Potential first-order effects of the time-invariant regional $\left(\boldsymbol{u}^{k}\right)$ and the common but time-varying elements $\left(\boldsymbol{x}_{t}\right)$ in $\mathbf{z}_{t}^{k}$ will be picked up by the regional fixed effects $\left(\delta_{U}^{k}\right)$ and the time effects $\left(\tau_{U t}\right)$ respectively, which we include in all regressions. Because our interest here is in the higher-order terms, i.e. in the impact of the characteristics $\mathbf{z}_{t}^{k \prime}$ on the slope coefficient on state output growth, this setup allows us to keep our regressions relatively parsimonious.
} 
and recognizing that $S D_{t}^{k}$ varies across time and states we obtain the following estimation equation:

$\Delta \widetilde{c}_{t}^{k}=\left[b_{U 0} \Delta g d p_{t}+b_{U 1} \Delta g d p_{t} \times S D_{t}^{k}+a_{U 0}+a_{U 1} S D_{t}^{k}\right] \times \widetilde{g s p}_{t}^{k}+c_{U} S D_{t}^{k}+\boldsymbol{d}_{U t}^{k \prime} \mathbf{1}+\varepsilon_{U t}^{k}$.

This particular equation is a differences-in-differences regression where deregulation is the treatment. As we will argue, deregulation weakens the covariation of risk sharing with GDP growth. In the above equation, this means that $b_{U 0}<0$ and $b_{U 1}>0$.

\subsection{Channels of risk sharing}

The coefficient $\beta_{U}$ in (2) tells us how much of the idiosyncratic risk faced by the average federal state remains uninsured at time $t$. To better understand the nature of the frictions that drive time variation in $\beta_{U}(t)$, we also want to know how risk sharing is achieved. Asdrubali, Sørensen and Yosha (1996) have proposed a framework that allows us to explicitly identify three such channels of interstate risk sharing. Here we refer to these channels as income smoothing, fiscal transfers and consumption smoothing. The method by Asdrubali et al. (1996) is based on a decomposition of the crosssectional variance of state output growth. To derive this decomposition, we rewrite state output growth tautologically as

$$
\Delta \widetilde{g s p}_{t}^{k}=\left[\Delta \widetilde{g s p}_{t}^{k}-\Delta \widetilde{s i}_{t}^{k}\right]+\left[\Delta \widetilde{s i}_{t}^{k}-\Delta \widetilde{d s i_{t}^{k}}\right]+\left[\Delta \widetilde{d s i}_{t}^{k}-\Delta \widetilde{c}_{t}^{k}\right]+\Delta \widetilde{c}_{t}^{k}
$$

where $s i$ and $d s i$ denote the logarithms of state-level income and disposable income respectively. We will discuss these income concepts 
shortly. Because all states face aggregate US-wide shocks that cannot be insured by definition, we again focus on the idiosyncratic, state-specific component of all variables and again denote it with a tilde. Taking the covariance with $\Delta \widetilde{g s p}_{t}^{k}$ on both sides and rearranging, we get

$$
\beta_{I}+\beta_{F}+\beta_{C}=1-\beta_{U}
$$

where

$$
\begin{aligned}
& \beta_{I}=\operatorname{cov}\left(\Delta \widetilde{g s p_{t}^{k}}-\Delta \widetilde{s i}_{t}^{k}, \Delta \widetilde{g s p_{t}^{k}}\right) / \operatorname{var}\left(\Delta \widetilde{g s p}_{t}^{k}\right), \\
& \beta_{F}=\operatorname{cov}\left(\Delta \widetilde{s i} i_{t}^{k}-\Delta \widetilde{d s i} i_{t}^{k}, \Delta \widetilde{g s p_{t}^{k}}\right) / \operatorname{var}\left(\Delta \widetilde{g s p_{t}^{k}}\right), \\
& \beta_{C}=\operatorname{cov}\left(\Delta \widetilde{d s i}{ }_{t}^{k}-\Delta \widetilde{c}_{t}^{k}, \Delta \widetilde{g s p}{ }_{t}^{k}\right) / \operatorname{var}\left(\Delta \widetilde{g s p_{t}^{k}}\right), \\
& \beta_{U}=\operatorname{cov}\left(\Delta \widetilde{c}_{t}^{k}, \Delta \widetilde{g s p}{ }_{t}^{k}\right) / \operatorname{var}\left(\Delta \widetilde{g s p_{t}^{k}}\right) .
\end{aligned}
$$

The four coefficients $\beta_{I}, \beta_{F}, \beta_{C}$ and $\beta_{U}$ provide us with a decomposition of the cross-sectional variance of state-specific output growth. The coefficient $\beta_{U}$ is the same as in the basic regression (1) above and measures the fraction of a typical state output shock that remains unshared. Conversely, the coefficients $\beta_{I}, \beta_{F}$ and $\beta_{C}$ provide a breakdown into the contribution of the different channels to aggregate risk sharing.

We refer to the first channel, captured by $\beta_{I}$, as income smoothing. Whereas state output measures the quantity of goods and services produced in the state, state income captures the value of goods and services owned by the state's residents. The wedge between the two variables is therefore a measure of net factor income flows ${ }^{8}$ and

\footnotetext{
${ }^{8}$ This is analogous to the difference between GDP and GNP in national income accounting. However, unlike GNP, state income does not reflect all income flows to a state. Specifically, it excludes income flows to legal entities (such as incorporated
} 
$\beta_{I}$ measures to what extent these cross-state income flows systematically buffer a state's income against fluctuations in its output.

Fiscal transfers are a second channel that may provide risk sharing, e.g. through the progressivity of the tax system, through the social security system or through other direct payments. Net fiscal transfers account for the difference between state income (SI) and state disposable income (DSI). The coefficient $\beta_{F}$ therefore indicates to what extent fiscal transfers allow residents of a federal state to smooth disposable income after a shock to state output.

Finally, a state's residents may save or dissave after observing their (disposable) income. We refer to this third channel as consumption smoothing, and we denote its contribution to overall risk sharing with $\beta_{C}$.

We call the vector $\boldsymbol{\beta}=\left[\beta_{I}, \beta_{F}, \beta_{C}, \beta_{U}\right]$ the pattern of risk sharing. At a practical level, this pattern can easily be estimated from the four regressions

$$
\begin{aligned}
& \Delta \widetilde{g s p_{t}^{k}}-\Delta \widetilde{s i}_{t}^{k}=\alpha_{I}+\beta_{I} \Delta \widetilde{g s p_{t}^{k}}+\delta_{I}^{k}+\varepsilon_{I t}^{k}, \\
& \Delta \widetilde{s i_{t}^{k}}-\Delta \widetilde{d s i_{t}^{k}}=\alpha_{F}+\beta_{F} \Delta \widetilde{g s p_{t}^{k}}+\delta_{F}^{k}+\varepsilon_{F t}^{k},
\end{aligned}
$$

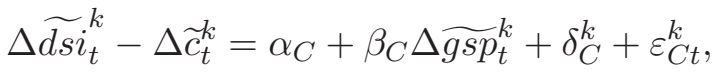

$$
\begin{aligned}
& \Delta \widetilde{c}_{t}^{k}=\alpha_{U}+\beta_{U} \Delta \widetilde{g s p_{t}^{k}}+\delta_{U}^{k}+\varepsilon_{U t}^{k},
\end{aligned}
$$

where the coefficients $\delta_{X}^{k}$ capture state-specific fixed effects. Note that the last equation is just the basic risk-sharing regression (1). The set of regressions (7) assumes that $\boldsymbol{\beta}$ is time-invariant. How-

firms) if this income is not eventually disbursed to private households. Because GNP data is not available at the state level, it is therefore not possible to disentangle risk sharing through net interstate factor income flows from the intrastate income smoothing achieved through the balance sheets of legal entities. 
ever, it is now straightforward to extend our setup from the previous subsection to allow the whole pattern of risk sharing (and not only the amount of unshared risk, $\beta_{U}(t)$ ) to vary over time. Specifically, for any of the channels $X=I, F, C$ we can estimate equations of the form (3) or (5) in the same way as we do for $X=U$. All we have to do is replace consumption growth $\left(\Delta \widetilde{c}_{t}^{k}\right)$ as a regressand with, in turn, $\Delta \widetilde{g s p_{t}^{k}}-\Delta \widetilde{s i}_{t}^{k}, \Delta \widetilde{s i}_{t}^{k}-\Delta \widetilde{d s i_{t}}$, and $\Delta \widetilde{d s i_{t}^{k}}-\Delta \widetilde{c}_{t}^{k}$ to characterize how the entire pattern of risk sharing varies across time and state.

\subsection{Data}

We use annual panel data for the 50 US states and for Washington DC for the period 1963-2005. To measure regional risk sharing on each level we employ an updated version of the data set compiled by Asdrubali et al. (1996). These data are compiled as follows.

- State Output (GSP). Our measure of state-level output is state gross domestic product from the Bureau of Economic Analysis (BEA). A conceptually very similar series was formerly published as gross state product (GSP) but has been discontinued. To avoid confusion between state-level and aggregate (US) variables, we nonetheless continue to refer to state-level output as GSP in this paper, and reserve the acronym GDP for US aggregate output.

- State Income $(S I)$. We use state personal income from the BEA, which is defined as the sum of earnings (wages and proprietors' income), profits (including interest and rent) dis- 
tributed to the state's residents and state and federal nonpersonal taxes (including corporate taxes and indirect business taxes).

- Disposable State Income ( $D S I)$. Disposable income is defined as state personal income plus federal transfers to individuals and federal grants to state governments minus federal nonpersonal taxes and contributions and federal personal taxes. Federal grants are provided by the United States Statistical Abstract, while federal personal taxes and transfers are available by state from the BEA.

- State Consumption $(C)$. State consumption is defined as the sum of private consumption and consumption by the state government. We follow Asdrubali et al. (1996) in constructing these data: state government consumption is state and local government expenditure less state and local transfers. Because private consumption at the state level is not available, we proxy it by retail sales, which we rescale by the ratio of aggregate US private consumption to aggregate US retail sales. Retail sales data by state have been updated from Asdrubali et al. (1996), and are available from the Statistical Abstract for the United States. They are sourced to Nielsen Claritas. For the years 1999 and 2003, however, these data are not available. We therefore proceed as follows: we obtain shopping center retail sales by state, which are available from the Statistical Abstract of the United States from 1990 to 2005. We then calculate the share of shopping center retail sales in to- 
tal retail sales and interpolate this share (which is quite stable over time for individual states) for the two years in which no observations of total state retail sales were available. We then multiply shopping center retail sales for these years with the interpolated share to obtain total retail sales by state. Total retail sales by state are then rescaled uniformly across states so as to make sure that the sum across states complies with the US-wide total retail sales as published by the BEA. ${ }^{9}$

All these variables are turned into real per capita variables using population data by state deflated with the Price Index of Personal Consumption Expenditure (PCE).

We consider two measures of small business importance in a federal state.

- Share of Proprietary Income (shapi). This is our primary measure. We calculate the share of proprietary income as the ratio of state proprietary income to state personal income. The data for both personal and proprietary income are from the BEA. Proprietary income is defined by the BEA as currentproduction income of sole proprietorships, partnerships, and tax-exempt cooperatives. It excludes dividends, monetary interest received by nonfinancial business, and rental income

\footnotetext{
${ }^{9}$ The adjustment factor is generally very close to one, suggesting that the approximation is quite reasonable. To check that none of our results depended on this interpolation, we also estimate all results in the paper including a year dummy for 1999 and 2003 in our regressions. This does not make a noticeable difference to our results.
} 
received by persons not primarily engaged in the real estate business.

- Small Business Employment $\left(S B E^{k}\right)$. This is the measure also used by Demyanyk et al. (2007). Small businesses are establishments with less than 100 employees. We measure small business employment as the number of people employed in small business establishments relative to total employment in a state in 1977. Unfortunately, this is the earliest date for which these data are available. The data were obtained from the Geospatial and Statistical Data Center, University of Virginia Library.

To model the dependence of aggregate risk sharing on the state of the business cycle we use the official real GDP growth series from the BEA and the peak and trough dates from the NBER businesscycle database. The impact of deregulation is proxied by an indicator variable. Specifically, we use data on intrastate banking deregulation from Demyanyk et al. (2007), Table 1. These go back to Kroszner and Strahan (1999) for the years after 1978 and Amel (1993) for the years before. Our state deregulation dummy $S D_{t}^{k}$ is zero before deregulation and is one from the year in which intrastate deregulation took place in state $k$ onwards, i.e. when the state permitted statewide branching by mergers and acquisitions. 


\subsection{Estimation issues}

We estimate all of our specifications by both OLS and GLS. In the latter case, we first estimate the respective equation for the entire panel by OLS. Then we estimate the residual variance for each state. In a second step, we correct for heteroskedasticity by weighting observations with the inverse of this state-specific variance. Though our main results generally come out more strongly under GLS, we mainly present OLS results in the paper, which give slightly higher weight to smaller states.

As a first guard against serial and cross-sectional dependence, all our specifications contain both time and region fixed effects. However, region fixed effects may be insufficient to control for more general forms of serial correlation at the regional level. As has been argued by Bertrand et al. (2004), the impact of serial correlation on the size of standard errors may be compounded in differencesin-differences specifications such as (6), where the regressands and the intervention dummy are often very persistent variables. As discussed in Petersen (2009), clustering is a quite general remedy in this setting because it does not require any specific assumptions about the functional form of serial dependence. Throughout the paper, we therefore report standard errors clustered by state to control for serial dependence at the state level. ${ }^{10}$

\footnotetext{
${ }^{10} \mathrm{We}$ use an adaptation of the MATLAB routine 'clusterreg.m', which is kindly made available on Ian Gow's web page: http://www.kellogg.northwestern.edu/faculty/gow/htm/GOT/matlab_routines.html.
} 


\section{Results}

\subsection{Cyclical patterns of interstate consumption risk shar- ing}

Table 1 provides the results of the channels decomposition (7) where we parameterize the risk-sharing pattern $\boldsymbol{\beta}(t)=\left[\begin{array}{llll}\beta_{I}(t), & \beta_{F}(t), & \beta_{C}(t), & \beta_{U}(t)\end{array}\right]^{\prime}$ as:

$$
\beta_{X}(t)=a_{X}+b_{X} \Delta g d p_{t}
$$

for $X=I, F, C, U$. As Figure 1 suggested, risk sharing is much less dependent on GDP in the second half of our sample period. We therefore split our sample into pre- and post-1984 subperiods and report results for these subperiods separately.

Confirming the intuition from Figure 1, we find that interstate consumption risk sharing increases in booms and decreases in recessions (i.e. $\beta_{U}(t)$ is countercyclical): in the early period, a one percentage point increase in aggregate GDP growth would have led to an almost 4 percentage point increase in interstate consumption risk sharing $\left(b_{U}=-3.7\right)$. However, we also find that this businesscycle dependence is limited mainly to the first period; in the second period, the estimate of $b_{U}$ is much closer to zero $(-0.98)$, and insignificant.

Turning to the patterns of risk sharing, we see that the main source of the procyclicality in risk sharing during the early period is consumption smoothing-our estimate of $b_{C}$ is positive and significant. This procyclicality in consumption smoothing is partly offset by income smoothing $\left(\beta_{I}(t)\right)$, which, interestingly, decreases in booms and rises in recessions. ${ }^{11}$

\footnotetext{
${ }^{11}$ Countercyclical income smoothing has also been observed by Agronin (2003),
} 
However, overall consumption smoothing $\left(\beta_{C}(t)\right)$ is much more strongly procyclical than income smoothing $\left(\beta_{I}(t)\right)$ is countercyclical. This impact on the procyclicality in aggregate risk sharing $\left(1-\beta_{U}(t)\right)$ is further reinforced through the fiscal channel, even though this effect is rather small and appears insignificant. Hence, fluctuations in access to consumption-smoothing possibilities are the main driver of the variation in interstate consumption risk sharing over the business cycle that we observe for the early period. In the second period, however, the cyclical pattern of income and consumption smoothing-though qualitatively similar-is much less pronounced: the associated coefficients $b_{C}$ and $b_{I}$ are now much closer to zero, and insignificant for both channels.

These findings are robust to alternative measures of the business cycle. In Panel B, we capture the business cycle using the official NBER peak and trough dates, again for the pre-1984 and post1984 periods. Here, we also distinguish between recessions and booms to check for the possibility of asymmetries in the dependence of risk sharing on the cycle. The impact of the business cycle on interstate risk sharing is again only significant for the first period. It also seems somewhat stronger in recessions: the point estimate on the recession dummy suggests that, at the trough of the average recession in our sample, risk sharing was 20 percentage points below its long-run mean. Conversely, the peak indicator has a coefficient of only -0.12 and appears insignificant. Turning to the channels,

who suggested that the explanation might be purely mechanical: the share of small business owners' income (proprietary income) in US output is strongly procyclical. Because income from small businesses is not generally disbursed across state boundaries, say through profit or dividend payments (because the owner of a typical small business is likely to reside in the state), the share of income that flows across state borders to provide income smoothing decreases in booms. 
we find that it is, again, the consumption-smoothing channel that accounts for this pattern: consumption smoothing seems to drop markedly in recessions. However, the evidence in favor of asymmetries is not overly strong: for both the unshared component and the consumption-smoothing channel, the coefficients on the expansion and recession indicators have absolute values that are not very far apart, and are oppositely signed throughout. Based on $F$-tests, we cannot reject the hypothesis that $b_{X 0}+b_{X 1}=0$ for $X=U, C$. We return to the potential role of asymmetries when we discuss the impact of state-level banking deregulation below.

\subsection{Importance of small businesses}

We show next that the cyclical pattern of interstate risk sharing is determined mainly by those states where small firms are important.

As discussed in the data description, we employ two measures of small firm importance in a state (which we denote $\mu$ throughout). First, we use the share of proprietary income in state personal income $(\mu=$ shapi). This measure specifically focuses on the importance for the regional economy of those households that actually own small businesses. Second, we use the share of total employment in small businesses of less than 100 employees $(\mu=S B E)$. This measure emphasizes the role of small businesses as employers, and therefore in the local economy at large. One drawback here is that state-level time series for small business employment are only available from 1977.

For both the employment- (SBE) and income- (shapi) based mea- 
sures, we split our sample of states into three equal-sized groups based on the importance of small businesses: high, middle or low. ${ }^{12}$ We conduct this sample split based on pre-1975 sample averages (by state) for the proprietors' income measure, whereas we use the earliest available observation (1977) for the employment-based measure of small business importance. ${ }^{13}$

We then rerun the regression specification (8) for the unsmoothed component, $\beta_{U}(t)$, on each of these groups, again based on two subperiods. The results are in Panel A of Table 2: in the first period, the coefficient on the interaction term between aggregate GDP, $\Delta g d p_{t}$, and the growth of gross state product, $\Delta \widetilde{g s p}_{t}^{k}$, is significantly negative for those states where small businesses are important. For the other two groups of states, aggregate risk sharing does not seem to covary significantly with the business cycle. The results are qualitatively the same, irrespective of whether we use the income- or the employment-based measure of small business importance. ${ }^{14}$

\footnotetext{
${ }^{12}$ This follows Demyanyk et al. (2007). We refer to these groups as high-, middleand low- $\mu$ groups.

${ }^{13} \mathrm{We}$ checked that it is indeed mainly the cross-sectional dispersion (and not time variation) in $\mu^{k}$ that drives the results. We parameterized many of the regressions below in a way that allows $\mu_{1}$ to vary across both time and state. Our results are robust to these changes. We focus on pre-1975 (or in the case of small business employment, the earliest available, i.e. 1977) observations for two reasons. First, because, as we argue below, the dependence of aggregate risk sharing on the business cycle (and the role of small business importance for the strength of this dependence) is weaker after the deregulation wave of the mid 1980s. Secondly, the recession of the early 1980s has had a major impact on the ranking of some big states in terms of small business importance.

${ }^{14}$ The coefficient $a_{U}$ may decline as we move from the low- to the high- $\mu$ group, but this does not necessarily mean that the high- $\mu$ group shares more risk on average. The reason for this variation in $a_{U}$ between the groups is mainly mechanical. We could equivalently estimate the specification $\beta_{U}(t)=\bar{a}_{U}^{i}+b_{U}^{i}\left(\Delta g d p_{t}-\overline{\Delta g d p}\right)$, where $\overline{\Delta g d p}$ is the sample mean of aggregate GDP growth and $i$ stands for the low, middle- and high- $\mu$ groups respectively. Then $\bar{a}_{U}^{i}=a_{U}^{i}-b_{U}^{i} \overline{\Delta g d p}$ is the average amount of risk shared by group $i$. It is apparent that the group with the higher business-cycle sensitivity (lower $b_{U}^{i}$ ) to risk sharing will necessarily have a lower $a_{U}^{i}$, if the average amount of risk shared, $\bar{a}_{U}^{i}$, does not vary across groups. We do not report the demeaned specification, because this would make the interpreta-
} 
Turning to the second period, however, we see that the cyclicality in risk sharing also vanishes for the high- $\mu$ states very much as it did when we considered all states.

We then explore to what extent the entire pattern of risk sharing is sensitive to the aggregate business cycle. We do so by parameterizing $\beta_{X}(t)$ as a function of the share of proprietary income in state personal income:

$$
\beta_{X}(t)=b_{X 0} \Delta g d p_{t}+b_{X 1} \Delta g d p_{t} \times\left(\mu^{k}-\bar{\mu}\right)+a_{X 0}+a_{X 1}\left(\mu^{k}-\bar{\mu}\right),
$$

where $\mu^{k}$ is the pre-1975 sample average of the share of proprietary income for state $k$ and $\bar{\mu}$ stands for the cross-sectional mean of $\mu^{k}$. Panel B of Table 2 presents the results for this specification. Again, the cyclical dependence of interstate risk sharing overall (i.e. of $\left.1-\beta_{U}(t)\right)$ is stronger where small firms account for a large share of state income. Inspecting the channels of risk sharing, we see that this feature can again primarily be explained by the fact that the consumption-smoothing channel, $\beta_{C}(t)$, is particularly procyclical in states where $\mu_{1}$ is high.

We conclude from these findings that the business-cycle dependence of interstate risk sharing is driven by the incidence of small businesses: not only is this dependence visible mainly in high- $\mu$ states. As the comparison over subperiods reveals, the dependence also disappears at roughly the same time, irrespective of whether we consider all states or just the high- $\mu$ states.

These stylized facts might, however, not be the result of a particular state having lots of small firms per se, but rather the outcome tion of the coefficients on $\Delta g d p$ less intuitive. 
of small firms being concentrated in particular sectors of the economy. Furthermore, the importance of small firms in a state could itself be endogenously determined by risk-sharing opportunities. We address these issues in turn.

\section{Robustness: controls for industrial structure, trends, etc.}

In Table 3A, we repeat our regressions for $\beta_{U}(t)$, but now we also include a number of controls to check for robustness. Specifically, we control for a state's industrial structure through a sectoral specialization index of the form

$$
I S^{k}=\sum_{s=1}^{S}\left\{\frac{G S P_{k}^{s}}{G S P_{k}}-\frac{1}{K-1} \sum_{j=1, j \neq k}^{K} \frac{G S P_{j}^{s}}{G S P_{j}}\right\}^{2},
$$

where $G S P_{k}^{s} / G S P_{k}$ is the share of value-added in sector $s$ in the total value-added of state $k$. In our regressions, we use the estimates of $I S^{k}$ provided in Table 1 of Kalemli-Ozcan, Sørensen and Yosha (2001) for both the one- and the two-digit industry classification levels. In our specification for $\beta_{U}(t)$ we then include both $I S^{k}$ and its interaction with $\Delta g d p$. We also add a linear trend in the specification for $\beta_{U}(t)$ to control for the effect of other, gradual developments that could have affected interstate risk sharing over the sample period. We present the results obtained from both the OLS- and the GLSbased specifications.

Table 3A provides the findings for the two sub-periods 196384 and 1985-2005. More specialized regions tend to be better insured, a stylized fact first established by Kalemli-Ozcan, Sørensen 
and Yosha $(2001,2003)$. However, our finding that risk sharing fluctuates significantly with GDP, and that it does so more strongly in states with many small businesses, remains unaffected. Furthermore, again, this pattern is no longer significant in the second part of the sample.

\section{Endogeneity of small business importance}

The importance of small businesses could be simultaneously determined with risk-sharing opportunities in a state. In principle, the impact of risk sharing on small firms could work either way: good risk-sharing opportunities (including in particular the continued access to financial markets in bad times) may foster the creation and survival of small firms, implying that better risk sharing might lead to a higher incidence of small firms in a state. If this was the case, any potential simultaneity bias would work against us in the regressions we have presented in this paper. We would then tend to underestimate any causal impact of small firms on the cyclicality of risk sharing. In principle, it is, however, also conceivable that small firms are most important in those states where risk sharing is lowest and most volatile. The reason might be that poor risk-sharing opportunities restrain firm growth, leading to a relatively high share of small firms in the state's economy. ${ }^{15}$

\footnotetext{
${ }^{15} \mathrm{We}$ also attempted to gauge which of the two sources of bias, if any, would dominate in the data. To this end, we make use of our result, presented in the next subsection, that banking deregulation improves risk sharing by removing its cyclicality. Because banking deregulation can be thought of as an exogenous improvement in risk sharing, we can ask whether it increases or lowers the importance of small businesses in a state. We ran regressions of the long-term change of small firm importance in a state on the year in which the state deregulated. Though insignificant for most specifications, these regressions suggest that states
} 
To ensure that our results are not unduly affected by endogeneity, we proxy small business importance using a remote lag of that variable. Plausibly, small business importance in the remote past is predetermined with respect to today's aggregate business-cycle shocks and, hence, with respect to current fluctuations in risksharing opportunities. We therefore rerun our previous specifications from Table 2 based on time averages by state of $\mu=$ shapi based on a period that ends well before our sample (the years 195055). Our results (presented in Table 3B) stay qualitatively the same. In the sample split, the coefficient on GDP growth is still much higher in the high- $\mu$ group than in the other two groups, and significant, though only at the 10 percent level. In the specification where the sensitivity of risk sharing to GDP growth is a linear function of $\mu$, the interaction between GDP and $\mu$ remains clearly significant and correctly signed in the specification for $\beta_{U}(t)$, for both the incomeand consumption-smoothing channels. Accounting for potential endogeneity of small firm importance does not affect our conclusion that risk sharing is more cyclical in high- $\mu$ states. And again, for both specifications, risk sharing varies significantly with the cycle only in the first half of the sample period.

\subsection{The role of banking deregulation}

We have shown that business-cycle fluctuations in risk sharing are much stronger in the first half of our sample than in the second.

that deregulated earlier tended to experience larger increases in small firm importance over the sample period. We conclude from this that if any significant simultaneity bias was present, it would lead us to underestimate the effect of small business importance on the cyclicality of risk sharing. 
Our maintained hypothesis is that small firms' access to credit markets, particularly to bank loans, is a key determinant of the extent to which interstate risk sharing fluctuates over the aggregate business cycle. A major development that could have affected the availability of credit to small firms in our sample period is the gradual deregulation of the US banking market during the 1970s and 1980s. Until then, the US had a highly fragmented, localized banking system. State regulation generally prohibited the operation of out-of-state banks and also strongly limited bank branching within a state. In some states, banks were only allowed to operate a single branch. ${ }^{16}$ From the point of view of economic theory, one would expect that the gradual lifting of this regulation would lead to considerable welfare gains through the formation of bigger banks and a better inter- and intrastate pooling of credit risk. Indeed, Jayaratne and Strahan (1996) showed that federal states that deregulated their banking markets earlier did eventually grow faster. They ascribed much of this growth gain to better access by small firms to credit. Morgan et al. (2004) found that deregulation has lowered the volatility of US state business cycles. In a recent important contribution, Demyanyk et al. (2007) demonstrated that income risk sharing increased because of state-level banking deregulation, and they also showed that this increase was more pronounced in states with many small businesses. While our paper is related to Demyanyk et al.'s, our analysis differs in scope. We focus on the role of proprietary businesses and state-level banking deregulation

\footnotetext{
${ }^{16}$ See Kroszner and Strahan (1999) for a succinct overview of the historical origins of this regulation and for a detailed account of the political and economic determinants of deregulation.
} 
for business-cycle variability in risk sharing rather than on the effect of deregulation on the average level of risk sharing. Specifically, we investigate to what extent banking deregulation has steadied interstate risk sharing.

The literature distinguishes between two dimensions of statelevel deregulation: intrastate deregulation removed branching and merger restrictions for banks and bank holding companies that were domiciled in a state, while interstate deregulation allowed access to the local market by out-of-state banks and bank holding companies (often on a reciprocal basis) thus making the interstate pooling of bank funds possible. Our focus in this paper is on intrastate deregulation. ${ }^{17}$

As explained in the data section, we exploit both the cross-sectional and intertemporal dimensions of deregulation by using a dummy variable $S D_{t}^{k}$, which becomes one from the year in which a state deregulates.

Table 4, Panel A shows the impact of banking deregulation on the cyclical pattern of risk sharing. Our specification for the risksharing pattern $\boldsymbol{\beta}^{k}(t)$, which we now estimate for the entire sample (1964-2005), is:

$$
\beta_{X}^{k}(t)=b_{X 0} \Delta g d p_{t}+b_{X 1} \Delta g d p_{t} \times S D_{t}^{k}+a_{X 0}+a_{X 1} S D_{t}^{k} .
$$

\footnotetext{
${ }^{17}$ In the working paper version (Hoffmann and Shcherbakova (2009)) we show that this focus on intrastate deregulation is justified: we run the regressions in this subsection based on the interstate deregulation indicator, finding that it is generally insignificant. We also ran a horse race between the intra- and interstate deregulation indicators, allowing both indicators to affect the cyclical dependence of risk sharing on GDP growth. Here, only intrastate deregulation had a significant impact on the variability of risk sharing over the cycle. Our results in this respect clearly tie in with the findings of Jayaratne and Strahan (1996), Morgan et al. (2004) and Demyanyk et al. (2007).
} 
For both the income- and consumption-smoothing channels, the coefficients $b_{X 0}$ and $b_{X 1}$ have opposite signs and are significant. For both channels, we cannot reject the hypothesis $b_{X 0}+b_{X 1}=0$ at conventional significance levels. For $\beta_{U}(t)$ we can equally not reject $b_{U 0}+b_{U 1}=0$, even though $b_{U 1}$ taken alone would just come close to the 10 percent significance level. ${ }^{18}$ These findings suggest that banking deregulation has virtually eliminated the businesscycle variation in aggregate risk sharing.

We again examine the robustness of our findings to alternative measures of the business cycle. Specifically, using the NBER peaks and troughs also allows us to investigate whether deregulation has had an asymmetric effect on risk sharing in booms and recessions. We estimate the following specification for the pattern of risk sharing:

$$
\beta_{X}^{k}(t)=b_{X 0} P_{t}+b_{X 1} T_{t}+b_{X 2} P_{t} \times S D_{t}^{k}+b_{X 3} T_{t} \times S D_{t}^{k}+a_{X 0}+a_{X 1} S D_{t}^{k}, \quad \text { (10) }
$$

where $P_{t}$ and $T_{t}$ are dummies indicating the NBER business cycle peaks and troughs respectively. The main feature of the results, presented in Panel B of Table 4, is that the deregulation dummy is strongly significant and negative in the interaction with the trough indicator. Conversely, the point estimate of the effect of deregulation at the peak of the business cycle is clearly insignificant. Deregulation seems to improve risk sharing mainly in recessions. In fact, the F-test that $b_{U 1}+b_{U 3}=0$ does not reject the null. Hence, deregulation virtually eliminates the large fall in interstate risk sharing that was

\footnotetext{
${ }^{18}$ In a GLS specification with clustered standard errors, $b_{U 1}$ is also significant at the 5 percent level. (t-stat of 2.6).
} 
characteristic of recessions before deregulation. ${ }^{19}$

As we documented earlier, business-cycle variation in interstate risk sharing is driven by states where small firms are particularly important. Therefore, we would expect that banking deregulation removed the business-cycle sensitivity of risk sharing in these 'high$\mu$ ' states. This is exactly what we saw in Table 2 : in the early part of the sample, the high- $\mu$ group is strongly exposed to fluctuations in GDP, whereas the low- and middle- $\mu$ groups are not. However in the later subsample, i.e. when most states had eventually deregulated, risk sharing no longer depended on GDP, even for the high- $\mu$ group.

In principle, it is conceivable that this pattern could be driven by other developments that coincided with the deregulation of bank branching restrictions. Not so: Table 5 shows that it is indeed the impact of banking deregulation that drives these results. We run the same regressions as in Table 2 A for the period 1964-84, but now we sort states into four categories: above/below median small business importance (high/low $\mu$ ) and whether the state had deregulated by 1984 or not (late/early deregulation). Risk sharing fluctuated significantly with GDP growth only in high- $\mu$ states that were late deregulators. For all other groups, in particular for the high- $\mu$ / early deregulation group, there is no significant link of $\beta_{U}(t)$ with aggregate GDP. Again, this holds true for both measures of small

\footnotetext{
${ }^{19}$ The results in Table 4 do not generally indicate that banking deregulation increases consumption risk sharing on average: the coefficient $a_{U 1}$ is insignificant in both Panel A and Panel B. According to the results in Panel B, income risk sharing increases $\left(a_{I 1}>0\right)$, which is consistent with Demyanyk et al. (2007), but consumption smoothing seems to decrease $\left(a_{C 1}<0\right)$. This could suggest that there is a potentially interesting shift in the long-term pattern of risk sharing following banking deregulation. Our focus here is on the effect of deregulation on the cyclicality in risk sharing, and we do not explore this issue further.
} 
business importance. ${ }^{20}$

\subsection{Interstate risk sharing and other cyclical factors}

Before we conclude, we briefly elaborate on the possibility that other cyclical factors that are highly correlated with aggregate GDP could drive time variation in risk sharing. Specifically, we check that the cyclicality in risk sharing that we have identified here is truly driven by the business cycle and not by fluctuations in asset values. This might be the case, because assets such as housing or stocks may serve as collateral, and fluctuations in their value might therefore lead to fluctuations in the availability of credit. We use Lettau and Ludvigson's (2001) cay residual as an indicator of asset price cycles, and Lustig and van Nieuwerburgh's (2005) housing collateral ratio as an indicator of the availability of mortgage credit. We then parameterize $\beta_{U}(t)$ as a function of these variables and of GDP growth. Both cay and the housing collateral ratio are generally significant in our specifications-asset prices and collateral availability are important determinants of interstate risk sharing. However, all our earlier conclusions concerning the role of GDP growth remain unaffected: i) risk sharing increases when GDP growth is high and

\footnotetext{
${ }^{20}$ We also conducted a Monte Carlo experiment to check whether developments other than banking deregulation could account for the vanishing cyclicality in risk sharing in the second half of the sample. We follow Bertrand et al. (2004) and Aghion et al. (2008) and assign 'placebo' deregulation dates to each state. The dates are drawn randomly from the empirical distribution of our $S D$ indicator. We repeat this procedure 1000 times and check in what fraction of cases these artificial interventions are significant in our regressions. We then also perform a horse race in which we include both the actual and the placebo deregulation dates in our regressions. All these experiments suggest that it is very unlikely that the vanishing cyclicality in risk sharing is associated with some event other than banking deregulation. See Hoffmann and Shcherbakova (2009) for details.
} 
decreases when it is low; ii) this pattern is determined by states with lots of small businesses; and iii) it vanishes with deregulation. Once again, see Hoffmann and Shcherbakova (2009) for detailed results.

\section{Conclusions}

In this paper, we established that interstate risk sharing in the United States varies over the business cycle, with risk sharing increasing in booms and decreasing during downturns. This variation in aggregate risk sharing is quantitatively important. Over our sample period, the average state would share almost 80 percent of its business-cycle risk with other states. However, every percentage point increase in US-wide GDP growth increases interstate risk sharing by almost four percentage points, and in the trough of the average recession in our sample period, risk sharing was almost 20 percentage points below its mean.

We also identified a distinct pattern in how risk is shared over the business cycle. Interestingly, we find that income smoothing through capital income flows is countercyclical, whereas consumption smoothing through saving and dissaving at the household level is strongly procyclical. It is the latter effect that dominates, so that aggregate risk sharing is also strongly procyclical.

We conjecture that these patterns of risk sharing are determined by time variation in the ability of small firms to obtain credit. First, we demonstrate that the business-cycle dependence of risk sharing is much more pronounced in states where small firms are particu- 
larly prevalent. Second, we show that the liberalization of state-level bank branching and holding legislation in the US has significantly affected this pattern: banking deregulation virtually removed the dependence of aggregate risk sharing on the business cycle, and this reduction in cyclical dependence occurred primarily in states where small businesses account for a large share of income or employment.

At a theoretical level, banking deregulation may affect risk sharing in two ways: first, better interstate pooling of credit risk may lead to more risk sharing on average. Second, if firms and households face collateral and borrowing constraints, the extent to which consumption risk sharing is possible may be sensitive to the phase of the business cycle. Our results are consistent with the view that this second effect is particularly important: banking deregulation seems to have improved credit market access for small firms most when it is most needed-in cyclical downturns. 


\section{References}

[1] Viral V. Acharya, Jean Imbs, and Jason Sturgess, Finance and efficiency: Do bank branching regulations matter?, CEPR Discussion Papers 6202 (2007).

[2] Philippe Aghion, Robin Burgess, Stephen Redding, and Fabrizio Zilibotti, The unequal effects of liberalization: Evidence from dismantling the License Raj in India, American Economic Review 98 (4) (2008), 1397-1412.

[3] Eugene Agronin, Risk sharing across the United States, proprietary income and the business cycle, manuscript, Harvard University, 2003.

[4] Dean Amel, State laws affecting the geographic expansion of commercial banks, manuscript, Board of Governors of the Federal Reserve System, 1993.

[5] Pierfederico Asdrubali, Bent E. Sørensen, and Oved Yosha, Channels of interstate risk sharing: United States 1963-1990, Quarterly Journal of Economics 111 (4) (1996), 1081-1110.

[6] Ben Bernanke, Non-monetary effects of the financial crisis in the propagation of the Great Depression, American Economic Review 73 (1983), 257-76.

[7] Ben Bernanke and Mark Gertler, Agency costs, net worth and business fluctuations, American Economic Review 79 (1989), $14-31$.

[8] Marianne Bertrand, Esther Duflo, and Sendhil Mullainathan, How much should we trust differences-in-differences estimates?, Quarterly Journal of Economics 119 (1) (2004), 249275.

[9] John H. Cochrane, A simple test of consumption insurance, Journal of Political Economy 99 (5) (1991), 957-76.

[10] Mario C. Crucini, On international and national dimensions of risk sharing, Review of Economics and Statistics 81 (1) (1999), 73-84.

[11] Yuliya Demyanyk, Charlotte Ostergaard, and Bent Sørensen, US banking deregulation, small businesses, and interstate insurance of personal income, Journal of Finance LXII, No. 6 (2007), 2763-2801. 
[12] Mark Gertler and Simon Gilchrist, Monetary policy, business cycles, and the behavior of small manufacturing firms, Buarterly Journal of Economics 109 (2) (1994), 309-40.

[13] Mathias Hoffmann and Iryna Shcherbakova, Consumption risk sharing over the business cycle: the role of small firms' access to credit markets, CESifo Working Paper 2544 (2009).

[14] Jith Jayaratne and Philip E. Strahan, The finance-growth nexus: Evidence from bank branch deregulation, Quarterly Journal of Economics 111 (3) (1996), 639-70.

[15] Sebnem Kalemli-Ozcan, Bent Sørensen, and Oved Yosha, Economic integration, industrial specialization, and the asymmetry of macroeconomic fluctuations, Journal of International Economics 55 (1) (2001), 107-37.

[16] _ Risk sharing and industrial specialization: Regional and international evidence, American Economic Review 93 (3) (2003), 903-18.

[17] Nobuhiro Kiyotaki and John Moore, Credit cycles, Journal of Political Economy 105 (2) (1997), 211-48.

[18] Randall S. Kroszner and Philip E. Strahan, What drives deregulation? Economics and politics of the relaxation of bank branching restrictions, Quarterly Journal of Economics 114 (4) (1999), 1437-67.

[19] Martin Lettau and Sydney Ludvigson, Consumption, aggregate wealth and expected stock returns, Journal of Finance LVI (3) (2001), 815-49.

[20] Hanno N. Lustig and Stijn G. Van Nieuwerburgh, Housing collateral, consumption insurance, and risk premia: An empirical perspective, Journal of Finance 60 (3) (2005), 1167-1219.

[21] Barbara Mace, Full insurance in the presence of aggregate uncertainty, Journal of Political Economy 99 (5) (1991), 928-56.

[22] Donald P. Morgan, Bertrand Rime, and Philip E. Strahan, Bank integration and state business cycles, Quarterly Journal of Economics 119 (4) (2004), 1555-85.

[23] Mitchell A. Petersen, Estimating standard errors in finance panel data sets: Comparing approaches, Review of Financial Studies 22 (1) (2009), 435-80. 
[24] Bent E. Sørensen, Yi-Tsu Wu, Oved Yosha, and Yu Zhu, Home bias and international risk sharing: Twin puzzles separated at birth, Journal of International Money and Finance 26 (2007), 587-605.

[25] Robert M. Townsend, Risk and insurance in village India, Econometrica 62 (1994), 539-91. 
Table 1: Risk Sharing and the Business Cycle

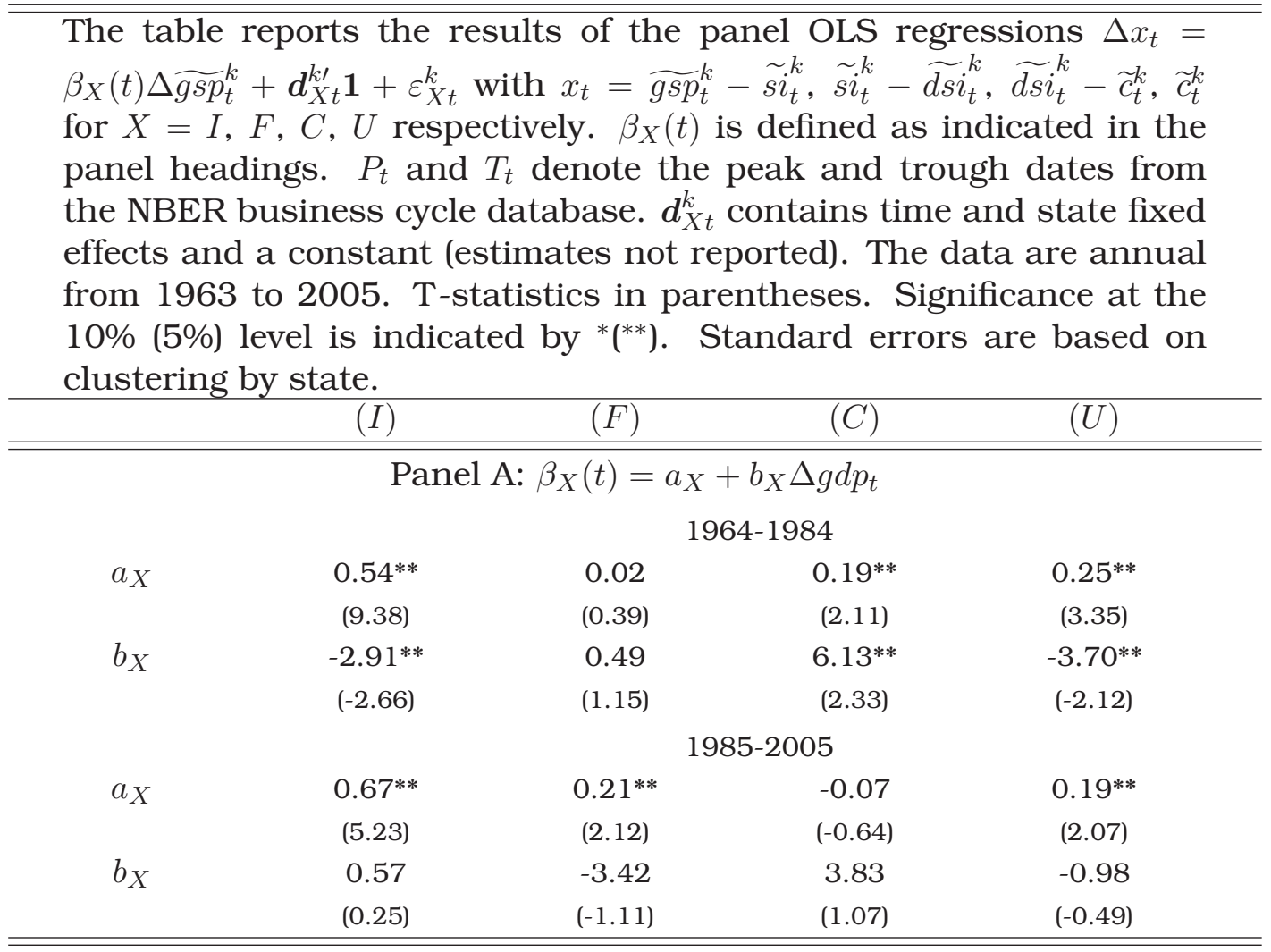

Panel B: $\beta_{X}(t)=a_{X}+b_{X 0} P_{t}+b_{X 1} T_{t}$

\begin{tabular}{ccccc}
\multicolumn{5}{c}{ Panel B: $\beta_{X}(t)=a_{X}+b_{X 0} P_{t}+b_{X 1} T_{t}$} \\
$a_{X}$ & $0.41^{* *}$ & $0.07^{* *}$ & $0.40^{* *}$ & $0.12^{* *}$ \\
& $(5.79)$ & $(3.28)$ & $(5.23)$ & $(2.26)$ \\
$b_{X 0}$ & 0.01 & -0.12 & $0.23)$ & -0.12 \\
& $(0.04)$ & $(-1.15)$ & $(1.67$ & $(-1.11)$ \\
$b_{X 1}$ & 0.13 & 0.00 & $-0.33^{* *}$ & $0.20^{* *}$ \\
& $(1.17)$ & $(0.06)$ & $(-1.98)$ & $(2.36)$ \\
& & & 0.06 & \\
$a_{X}$ & $0.70^{* *}$ & $0.08^{* *}$ & $0.1985-2005$ & $0.16^{* *}$ \\
& $(9.03)$ & $(3.07)$ & $(0.68)$ & $(3.64)$ \\
$b_{X 0}$ & $-0.30^{* *}$ & 0.05 & 0.08 & 0.18 \\
& $(-3.72)$ & $(0.34)$ & $(0.46)$ & $(1.06)$ \\
$b_{X 1}$ & $0.12^{* *}$ & 0.14 & -0.09 & -0.17 \\
& $(2.00)$ & $(1.00)$ & $(-0.40)$ & $(-1.54)$
\end{tabular}

F-Test (p-value) of $H_{0}$ : Symmetry of expansion and recession (1964-1984)
$H_{0}$ :
F-Test $=1.58$
F-Test $=0.86$
F-Test $=0.49$
F-Test $=0.80$
$b_{X 0}+b_{X 1}=0$
$(0.21)$
(0.36)
$(0.48)$
(0.37) 
Table 2: Risk Sharing and Small Business Importance

Panel A reports the results of the panel OLS regression $\Delta \widetilde{c}_{k, t}=\beta_{U}(t) \Delta \widetilde{g s p}_{t}^{k}+$ $\boldsymbol{d}_{U t}^{k \prime} \mathbf{1}+\varepsilon_{U t}^{k}$ for two periods: pre-1984 and post-1984. $\beta_{U}(t)$ is defined as $\beta_{U}(t)=a_{U}+b_{U} \Delta g d p_{t}$. The states are split into groups according to the importance of small businesses ("low", "middle", "high") $\mu^{k}$. Panel B reports the results of the panel OLS regressions $\Delta x_{t}=\beta_{X}^{k}(t) \Delta \widetilde{g s p_{t}^{k}}+\boldsymbol{d}_{X t}^{k \prime} \mathbf{1}+\varepsilon_{X t}^{k}$ with $x_{t}=\widetilde{g s p}_{t}^{k}-\widetilde{s i}_{t}^{k}, \widetilde{s i}_{t}^{k}-\widetilde{d s i} i_{t}^{k}, \widetilde{d s i} i_{t}^{k}-\widetilde{c}_{t}^{k}, \widetilde{c}_{t}^{k}$ for $X=I, F, C, U$ respectively for two periods: pre-1984 and post-1984. $\beta_{X}^{k}(t)$ is defined as indicated in the panel heading. $\mu^{k}$ denotes time-series means of the share of proprietary income for every state $k$ in the period from 1964 to 1975 and $\bar{\mu}$ is the crosssectional mean of $\mu^{k} . \boldsymbol{d}_{X t}^{k}$ contains time and state fixed effects and the constant (estimates not reported). The data are annual from 1963 to 2005. T-statistics in parentheses. Significance at the 10\% (5\%) level is indicated by $\left.{ }^{*}{ }^{* *}\right)$. In both panels standard errors are based on clustering by state.

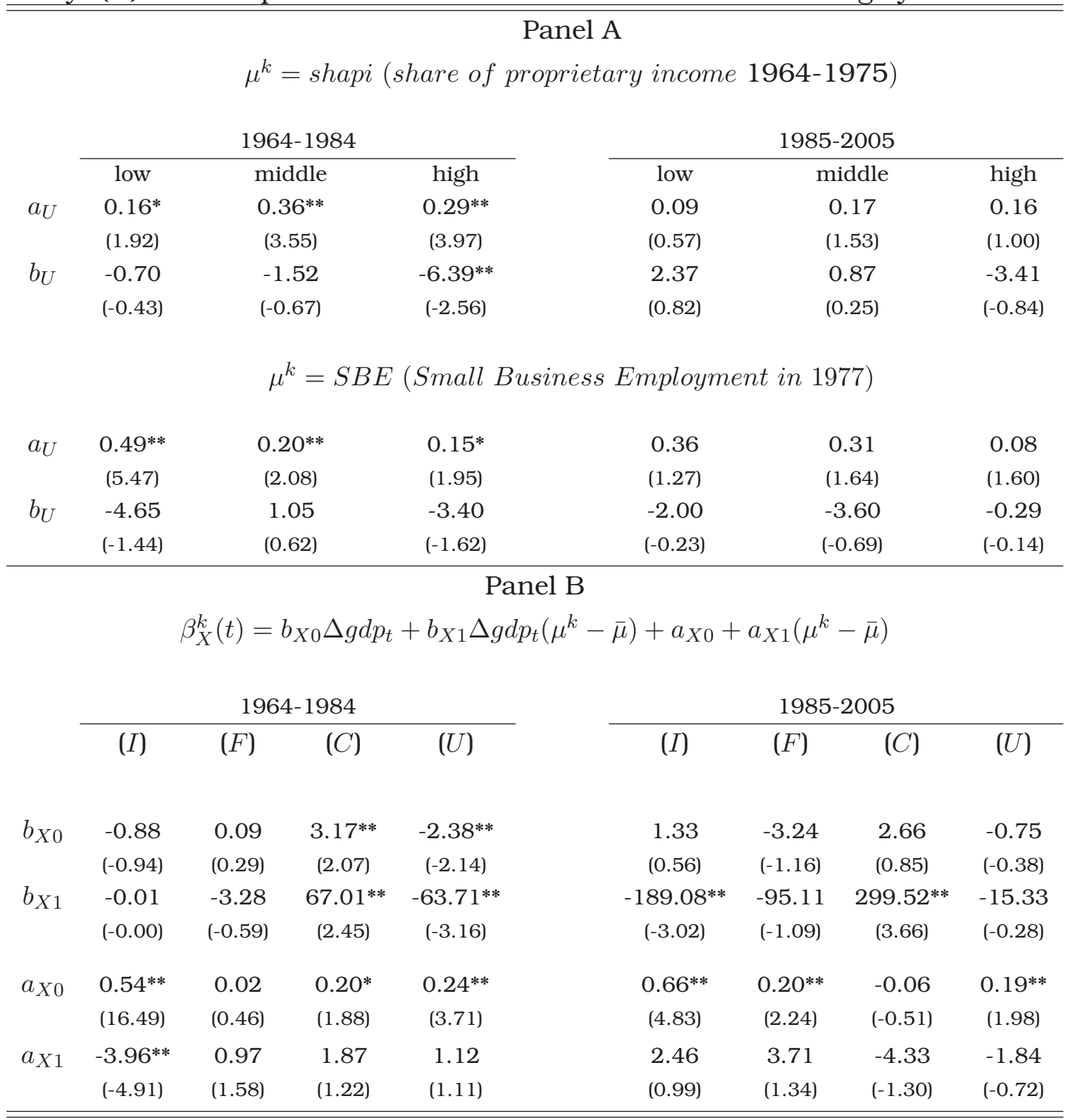




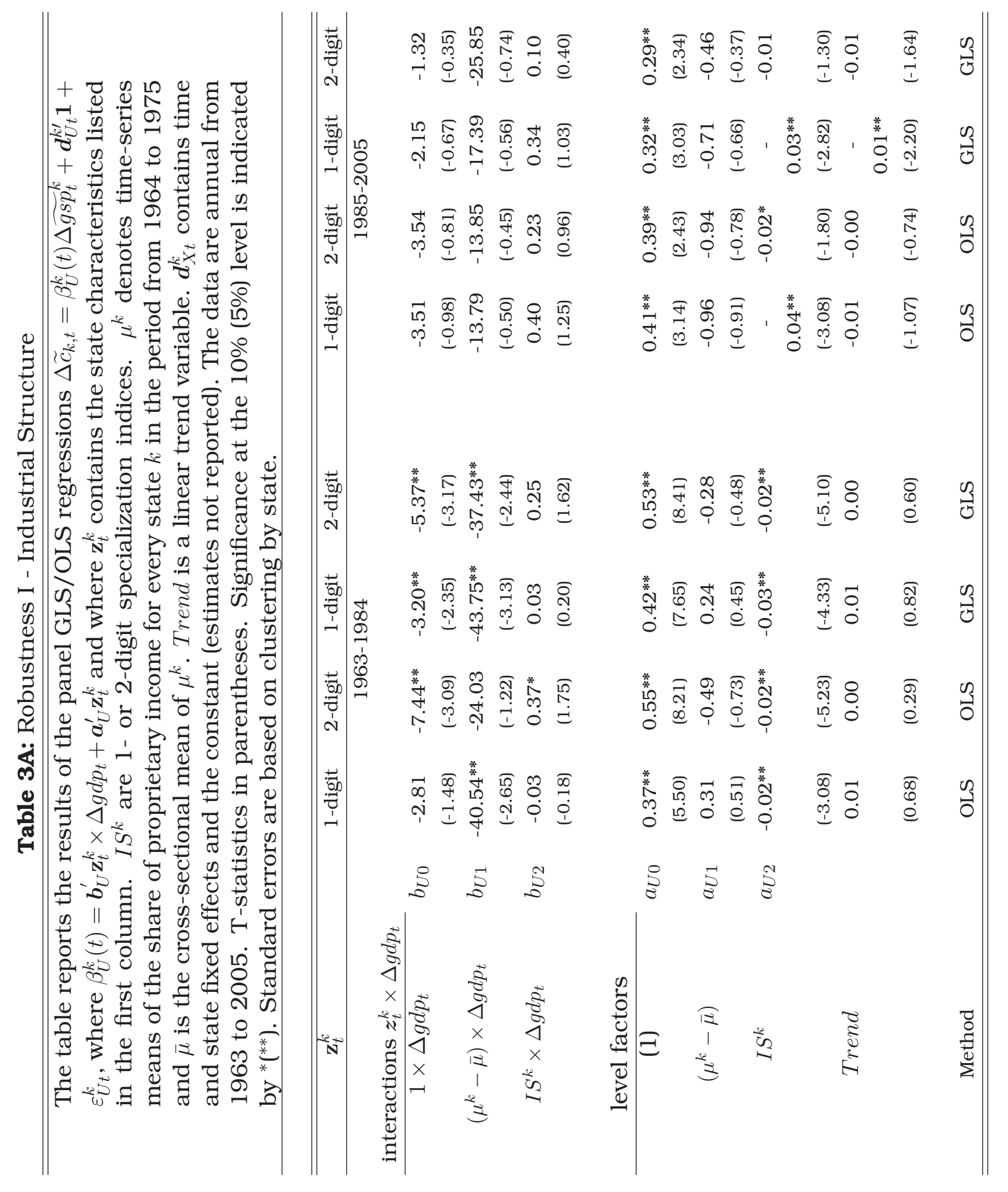


Table 3B: Robustness II - Lagged Small Business Importance

\begin{tabular}{l}
\hline \hline Panel A reports the results of the panel OLS regression $\Delta \widetilde{c}_{k, t}=\beta_{U}(t) \Delta \widetilde{g s p_{t}^{k}+}$ \\
$\boldsymbol{d}_{U t}^{k \prime} \mathbf{1}+\varepsilon_{U t}^{k}$ for two periods: pre-1984 and post-1984. $\beta_{U}(t)$ is defined as \\
$\beta_{U}(t)=a_{U}+b_{U} \Delta g d p_{t}$. The states are split into groups according to the im- \\
portance of small businesses ("low", "middle", "high") $\mu^{k}$. Panel B reports \\
the results of the panel OLS regressions $\Delta x_{t}=\beta_{X}^{k}(t) \Delta \widetilde{g s p_{t}^{k}}+\boldsymbol{d}_{X t}^{k} \mathbf{1}+\varepsilon_{X t}^{k}$ with \\
$x_{t}=\widetilde{g s p}_{t}^{k}-\widetilde{s i}_{t}^{k}, \widetilde{s i}_{t}^{k}-\widetilde{d s i}_{t}^{k}, \widetilde{d s i}_{t}^{k}-\widetilde{c}_{t}^{k}, \widetilde{c}_{t}^{k}$ for $X=I, F, C, U$ respectively for two \\
periods: pre-1984 and post-1984. $\beta_{X}^{k}(t)$ is defined as indicated in the panel \\
heading. $\mu^{k}$ denotes time-series means of the share of proprietary income for \\
every state $k$ in the period from 1950 to 1955 and $\bar{\mu}$ is the cross-sectional \\
mean of $\mu^{k}$. $\boldsymbol{d}_{X t}^{k}$ contains time and state fixed effects and the constant (esti- \\
mates not reported). The data are annual from 1963 to 2005 . T-statistics in \\
parentheses. Significance at the $10 \%(5 \%)$ level is indicated by ${ }^{*}\left({ }^{* *}\right)$. In both \\
panels standard errors are based on clustering by state.
\end{tabular}

Panel A

$\mu^{k}=$ shapi (share of proprietary income 1950-1955)

1964-1984

\begin{tabular}{|c|c|c|c|c|c|c|}
\hline & & & & & & \\
\hline & low & middle & high & low & middle & high \\
\hline \multirow[t]{2}{*}{$a_{U}$} & $0.15^{*}$ & $0.38^{* *}$ & $0.28^{* *}$ & 0.10 & $0.20^{*}$ & 0.14 \\
\hline & (1.87) & (3.81) & (3.39) & $(0.63)$ & (1.71) & $(1.21)$ \\
\hline \multirow[t]{2}{*}{$b_{U}$} & 0.09 & -4.00 & $-5.22^{*}$ & 2.05 & 1.34 & -4.01 \\
\hline & $(0.06)$ & $(-1.53)$ & $(-1.73)$ & (0.69) & $(0.42)$ & $(-1.14)$ \\
\hline
\end{tabular}

Panel B

\begin{tabular}{|c|c|c|c|c|c|c|c|c|}
\hline & \multicolumn{8}{|c|}{$\beta_{X}^{k}(t)=b_{X 0} \Delta g d p_{t}+b_{X 1} \Delta g d p_{t} \times\left(\mu^{k}-\bar{\mu}\right)+a_{X 0}+a_{X 1}\left(\mu^{k}-\bar{\mu}\right)$} \\
\hline & $(I)$ & $(F)$ & (C) & $(U)$ & $(I)$ & $(F)$ & (C) & $(U)$ \\
\hline \multirow[t]{2}{*}{$b_{X 0}$} & -0.86 & -0.12 & $4.14^{* *}$ & $-3.15^{* *}$ & 0.28 & -3.92 & 4.91 & -1.27 \\
\hline & $(-0.94)$ & $(-0.36)$ & (3.19) & $(-2.70)$ & $(0.12)$ & $(-1.14)$ & $(1.28)$ & $(-0.76)$ \\
\hline \multirow[t]{2}{*}{$b_{X 1}$} & -7.03 & -2.38 & $44.95^{* *}$ & $-35.54^{* *}$ & -36.09 & -23.20 & $80.84^{* *}$ & -21.56 \\
\hline & $(-0.81)$ & $(-0.81)$ & (3.05) & $(-2.89)$ & $(-0.97)$ & $(-1.00)$ & $(2.10)$ & $(-1.21)$ \\
\hline \multirow[t]{2}{*}{$a_{X 0}$} & $0.50^{* *}$ & 0.04 & $0.21^{* *}$ & $0.26^{* *}$ & $0.65^{* *}$ & $0.23^{* *}$ & -0.07 & $0.19^{* *}$ \\
\hline & $(12.52)$ & (1.14) & $(2.25)$ & $(4.82)$ & (6.36) & $(2.05)$ & $(-0.60)$ & (2.43) \\
\hline \multirow[t]{2}{*}{$a_{X 1}$} & $-1.93^{* *}$ & $0.73^{* *}$ & 0.49 & 0.70 & -0.45 & 0.81 & -0.50 & 0.14 \\
\hline & $(-3.97)$ & (1.96) & $(0.45)$ & $(1.11)$ & $(-0.30)$ & $(1.09)$ & $(-0.36)$ & (0.15) \\
\hline
\end{tabular}


Table 4: Risk Sharing, Banking Deregulation and the Business Cycle (OLS) The table reports the results of the panel OLS regressions $\Delta x_{t}=$ $\beta_{X}^{k}(t) \Delta \widetilde{g s p_{t}^{k}}+c_{X} S D_{t}^{k}+\boldsymbol{d}_{X t}^{k \prime} \mathbf{1}+\varepsilon_{X t}^{k}$ with $x_{t}=\widetilde{g s p_{t}^{k}}-\widetilde{s i}_{t}^{k}, \widetilde{s i}_{t}^{k}-\widetilde{d s i_{t}^{k}}, \widetilde{d s i_{t}^{k}}-\widetilde{c}_{t}^{k}, \widetilde{c}_{t}^{k}$ for $X=I, F, C, U$ respectively. $\beta_{X}(t)$ is defined as indicated in the panel heading. $S D_{t}^{k}$ is the intrastate deregulation dummy, which is 1 from the year of state $k$ 's intrastate deregulation onwards. $P_{t}$ and $T_{t}$ are dummies for the peak and trough dates from the NBER business cycle database. $\boldsymbol{d}_{X t}^{k}$ contains time and state fixed effects and the constant (estimate not reported). $c_{X}$ is not reported. The data are annual from 1963 to 2005. T-statistics in parentheses. Significance at the $10 \%(5 \%)$ level is indicated by ${ }^{*}\left({ }^{*}\right)$. In both panels standard errors are based on clustering by state.

\begin{tabular}{|c|c|c|c|c|}
\hline & $(I)$ & $(F)$ & $(C)$ & $(U)$ \\
\hline \multicolumn{5}{|c|}{ Panel A: $\beta_{X}^{k}(t)=b_{X 0} \Delta g d p_{t}+b_{X 1} \Delta g d p_{t} \times S D_{t}^{k}+a_{X 0}+a_{X 1} S D_{t}^{k}$} \\
\hline \multirow[t]{2}{*}{$b_{X 0}$} & $-4.29^{* *}$ & 0.30 & $10.07^{* *}$ & $-6.08^{* *}$ \\
\hline & $(-3.59)$ & $(1.06)$ & (3.90) & $(-3.08)$ \\
\hline \multirow[t]{2}{*}{$b_{X 1}$} & $4.44^{* *}$ & 0.59 & $-9.24^{* *}$ & 4.21 \\
\hline & $(2.56)$ & $(0.71)$ & $(-2.31)$ & (1.53) \\
\hline \multirow[t]{2}{*}{$a_{X 0}$} & $0.55^{* *}$ & $0.09 * *$ & 0.01 & $0.35^{* *}$ \\
\hline & (9.74) & $(6.17)$ & (0.09) & (5.90) \\
\hline \multirow[t]{2}{*}{$a_{X 1}$} & 0.08 & -0.08 & 0.13 & -0.13 \\
\hline & (1.32) & $(-1.57)$ & (1.30) & $(-1.44)$ \\
\hline
\end{tabular}

Panel B: $\beta_{X}^{k}(t)=b_{X 0} P_{t}+b_{X 1} T_{t}+b_{X 2} P_{t} \times S D_{t}^{k}+b_{X 3} T_{t} \times S D_{t}^{k}+a_{X 0}+a_{X 1} S D_{t}^{k}$

$\begin{array}{lcccc}b_{X 0} & -0.15 & -0.00 & 0.29^{* *} & -0.13 \\ b_{X 1} & (-1.47) & (-0.16) & (2.03) & (-1.59) \\ & 0.24^{* *} & -0.00 & -0.53^{* *} & 0.30^{* *} \\ b_{X 2} & (2.76) & (-0.23) & (-3.65) & (3.46) \\ & 0.16 & -0.21 & -0.04 & 0.09 \\ b_{X 3} & (0.82) & (-1.29) & (-0.21) & (0.53) \\ & -0.29^{* *} & 0.01 & 0.53^{* *} & -0.25^{* *} \\ a_{X 0} & (-2.74) & (0.29) & (3.02) & (-2.40) \\ & 0.41^{* *} & 0.10^{* *} & 0.35^{* *} & 0.14^{* *} \\ a_{X 1} & (7.95) & (9.07) & (3.84) & (2.93) \\ & 0.24^{* *} & -0.03 & -0.24^{* *} & 0.03 \\ & (3.26) & (-1.10) & (-3.10) & (0.54)\end{array}$

F-Test (p-value) of $H_{0}$ : Deregulation removes cyclicality in risk sharing ... in booms
$H_{0}: b_{X 0}+b_{X 2}=0$
F-Test $=0.08$
F-Test $=0.08$
F-Test $=0.08$
F-Test $=0.10$
(0.78)
(0.77)
(0.78)
(0.75)

in recessions

$\begin{array}{ccccc}H_{0}: b_{X 1}+b_{X 3}=0 & \text { F-Test }=0.29 & \text { F-Test }=1.12 & \text { F-Test }=0.11 & \text { F-Test }=0.48 \\ & (0.59) & (0.29) & (0.74) & (0.49)\end{array}$


Table 5: Risk Sharing, Banking Deregulation and Small Businesses The table reports the results of the panel OLS regression for the period 1964-1984 $\Delta \widetilde{c}_{k, t}=\beta_{U}(t) \Delta \widetilde{g s p}_{t}^{k}+\boldsymbol{d}_{U t}^{k \prime} \mathbf{1}+\varepsilon_{U t}^{k}$, where $\beta_{U}(t)=$ $a_{U}+b_{U} \Delta g d p_{t}$. The states are split into four categories: above/below median small business importance and whether the state had already deregulated by 1984 or not (early/late deregulation). $\boldsymbol{d}_{X t}^{k}$ contains time and state fixed effects and the constant (estimates not reported). The data are annual from 1963 to 1984 . T-statistics in parentheses. Significance at the 10\% (5\%) level is indicated by *(**). Standard errors are based on clustering by state. "Obs." denotes the number of observations in the respective category.

\begin{tabular}{|c|c|c|c|c|}
\hline & \multicolumn{4}{|c|}{$\mu^{k}=$ shapi (share of proprietary income 1964-1975) } \\
\hline & \multicolumn{2}{|c|}{ early deregulation } & \multicolumn{2}{|c|}{ late deregulation } \\
\hline & low $\mu^{k}$ & high $\mu^{k}$ & low $\mu^{k}$ & high $\mu^{k}$ \\
\hline \multirow[t]{2}{*}{$a_{U}$} & $0.14^{*}$ & $0.37^{* *}$ & $0.42^{* *}$ & $0.26^{* *}$ \\
\hline & (1.82) & (2.44) & (4.58) & (3.63) \\
\hline \multirow[t]{2}{*}{$b_{U}$} & -0.82 & -6.69 & -2.42 & $-6.38^{* *}$ \\
\hline & $(-0.53)$ & $(-1.55)$ & $(-1.11)$ & $(-2.91)$ \\
\hline \multirow[t]{4}{*}{ Obs. } & 378 & 126 & 147 & 420 \\
\hline & \multicolumn{4}{|c|}{$\mu^{k}=S B E($ Small Business Employment in 1977) } \\
\hline & \multicolumn{2}{|c|}{ early deregulation } & \multicolumn{2}{|c|}{ late deregulation } \\
\hline & low $\mu^{k}$ & high $\mu^{k}$ & low $\mu^{k}$ & high $\mu^{k}$ \\
\hline \multirow[t]{2}{*}{$a_{U}$} & $0.47^{* *}$ & $0.12^{*}$ & $0.30^{* *}$ & $0.23^{* *}$ \\
\hline & $(4.47)$ & (1.85) & (3.04) & (3.19) \\
\hline \multirow[t]{2}{*}{$b_{U}$} & -2.15 & -1.97 & -3.03 & $-5.41^{* *}$ \\
\hline & $(-0.46)$ & $(-0.89)$ & $(-1.58)$ & $(-2.30)$ \\
\hline Obs. & 315 & 189 & 210 & 357 \\
\hline
\end{tabular}




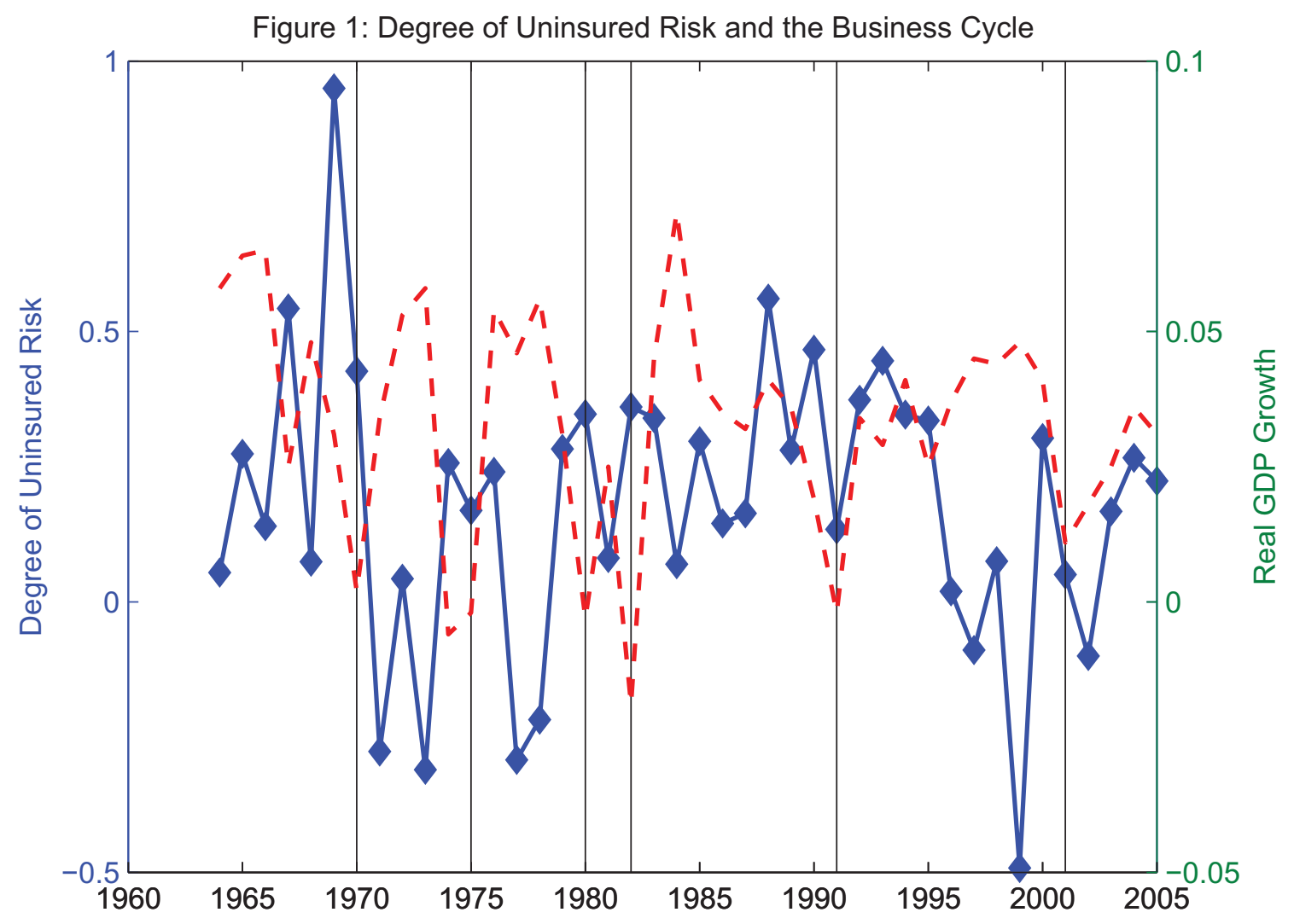

FIGURE 1: The blue, solid line is the coefficient $\beta_{U}(t)$ of the sequence of crosssectional regressions $\Delta \widetilde{c}_{t}^{k}=\beta_{U}(t) \Delta \widetilde{g s p}_{t}^{k}+\tau_{t}+\varepsilon_{t}^{k}$ for $t=1964 \ldots 2005$. The red, dashed line is US GDP growth. Vertical lines indicate NBER business cycle troughs. 


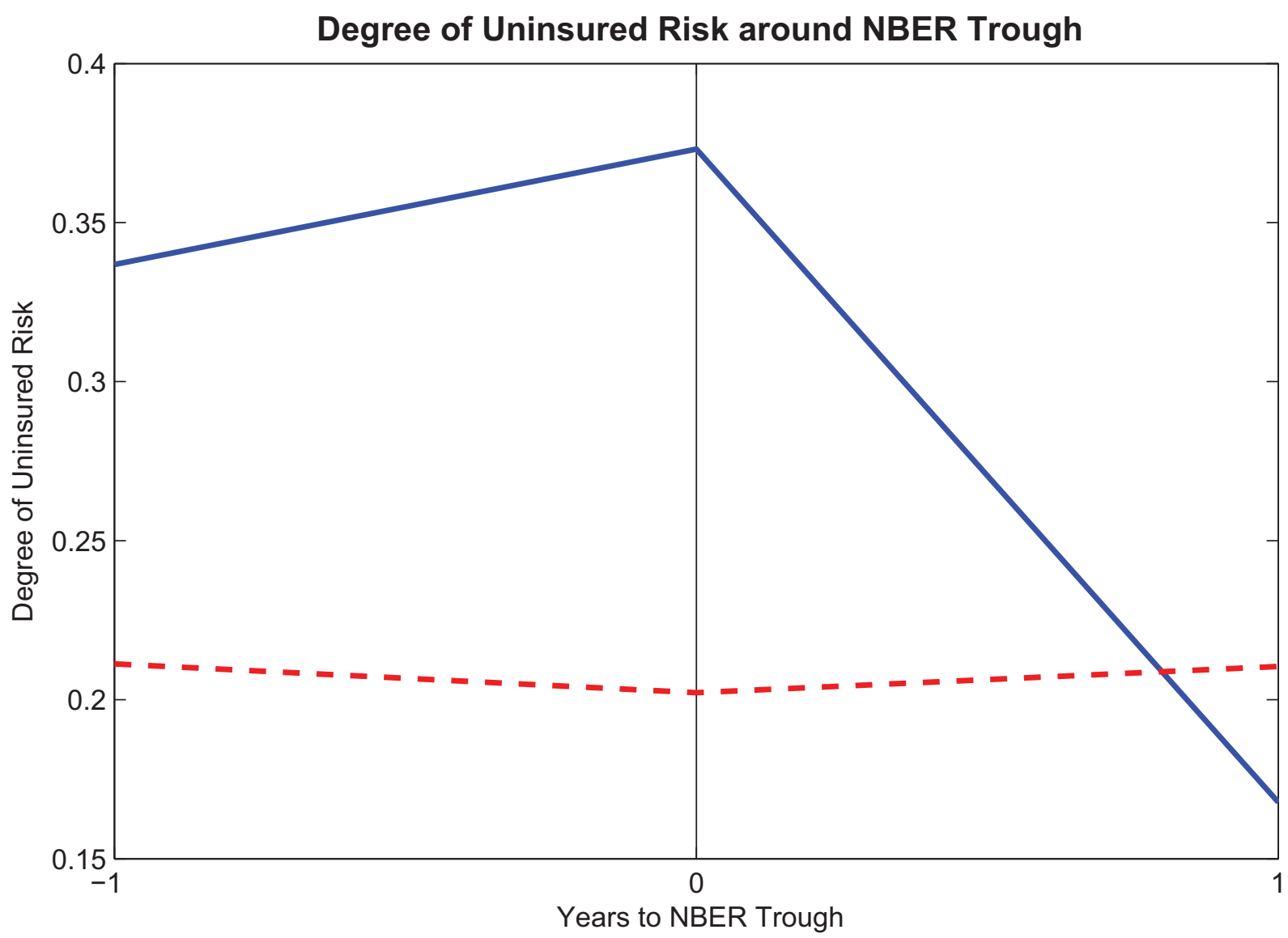

FIGURE 2: Burns-Mitchell diagram of the fraction of unshared risk around NBER recession troughs, distinguishing between states that have not yet (blue, solid line) and those that have already (red, dashed line) deregulated. This fraction was estimated as follows:

Let $I_{\text {trough }}=\left\{t_{\text {trough }}^{1} \ldots . . t_{\text {trough }}^{N}\right\}$ define the set of NBER trough dates. Altogether, our sample contains $N=6 \mathrm{NBER}$ recession troughs that define a total of $306=6 \times 51$ (50 states+ Washington D.C.) state-recession events. At each trough date, we split the 51 state-recession events into two groups, according to whether state $k$ had deregulated at that trough $t \in I_{\text {trough }}$ or not. We then pool state-recession events (by group) across all troughs and run the cross-sectional regressions $\Delta \widetilde{c}_{t+l}^{k}=\beta_{U}(l) \Delta \widetilde{g s p} p_{t+l}^{k}+\tau_{t+l}+\varepsilon_{t+l}^{k}$ for $l=-1,0,1$ and $t \in I_{\text {trough }}$, once for deregulated and once for not-yet-deregulated state-recession events. In this way, we obtain the typical time profile of risk sharing for each group one year before a trough $(l=-1)$, in the year of trough itself $(l=0)$ and one year after $(l=1)$. The plot gives the estimated $\beta_{U}(l)$ for the two groups. 
4tmos das jeey

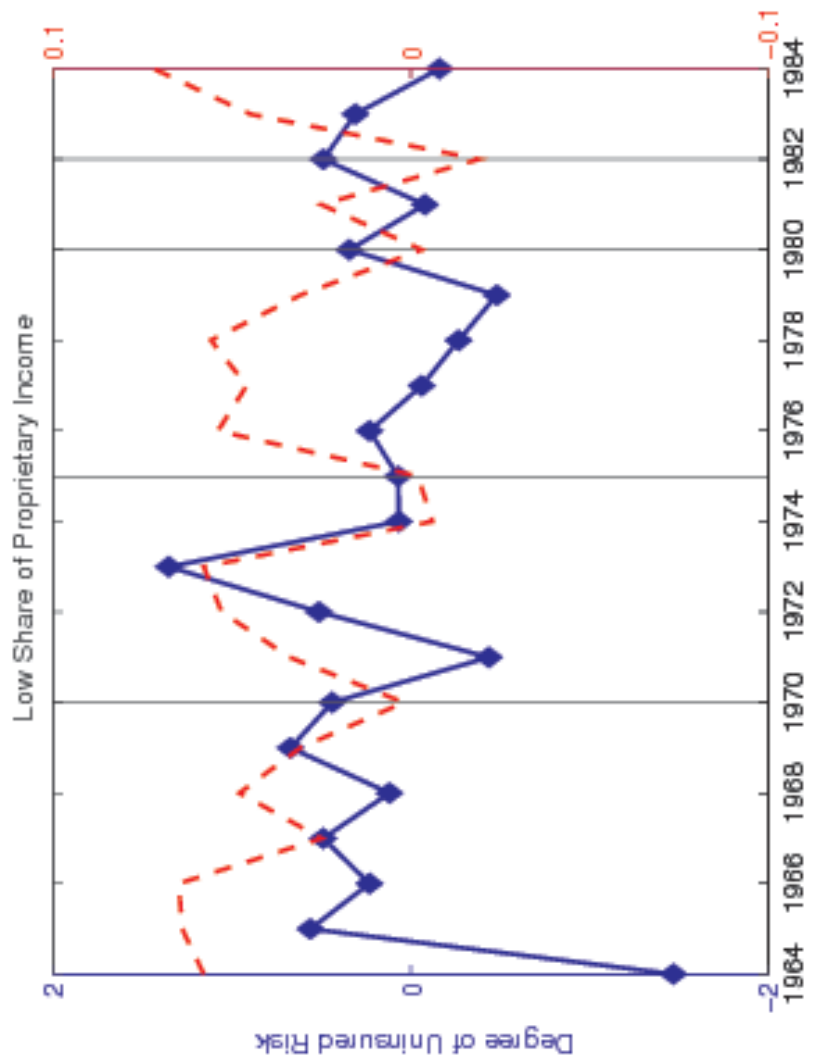

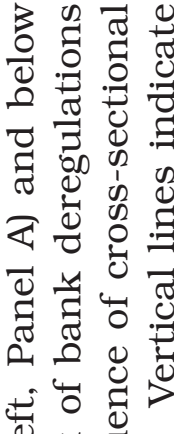

$\frac{1}{4}$

幽 头

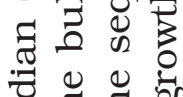

चु \&

凹

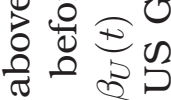

돌.

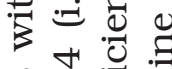

\& $\infty$

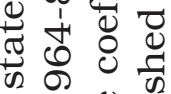

○一

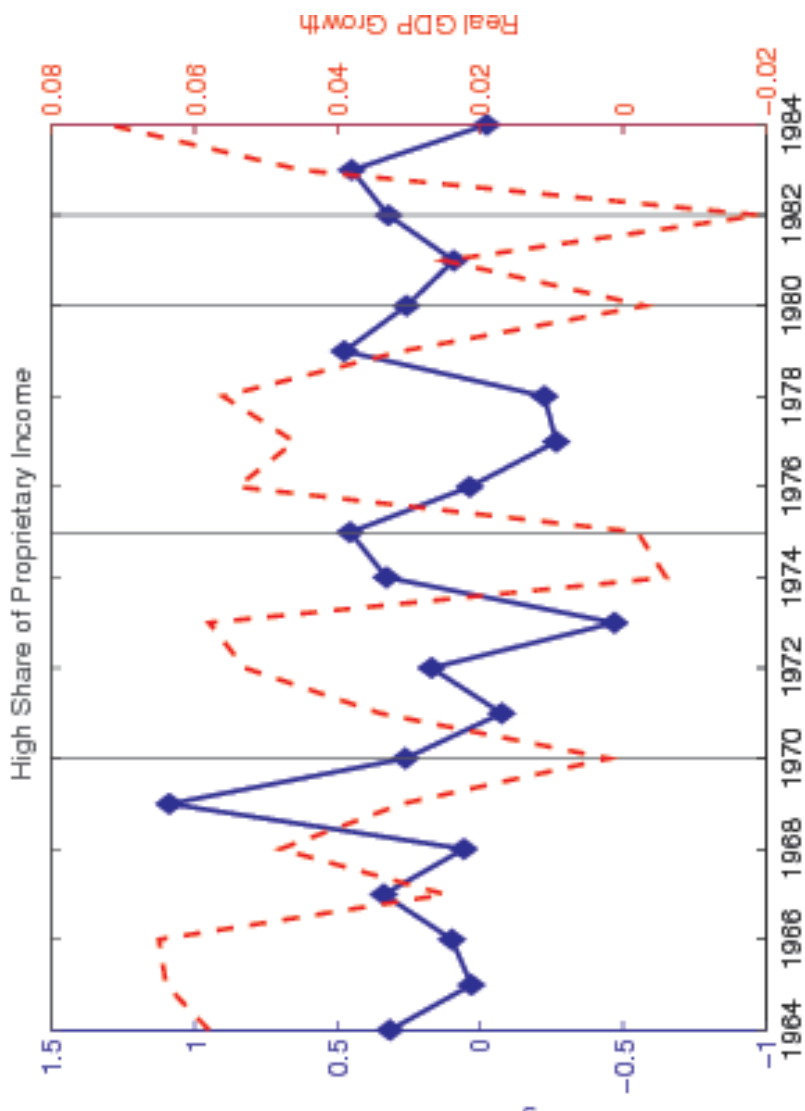

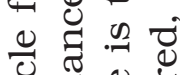

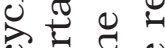

ठิ

की

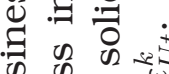

की की के

을 灵

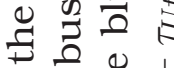

宊氠 +

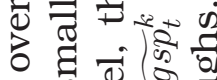

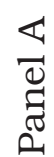

on क

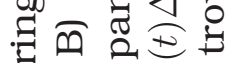

త్ర

त त

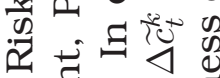

$\ddot{i} \dot{0} \dot{\theta} \approx$

(1) $\Xi$ ల

될 त्ञ

$\sigma$ चु

红 巳

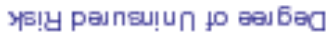

